\title{
Removal of veterinary antibiotics from swine wastewater using anaerobic and aerobic
} biodegradation

Han, Yuefei; Yang, Linyan; Chen, Xueming; Cai, Yu; Zhang, Xinyue; Qian, Mengcheng; Xingkui, Mao; Zhao, Huihui; Sheng, Mei; Cao, Guomin

Total number of authors:

11

Published in:

Science of the Total Environment

Link to article, DOI:

10.1016/j.scitotenv.2019.136094

Publication date:

2020

Document Version

Peer reviewed version

Link back to DTU Orbit

Citation $(A P A)$ :

Han, Y., Yang, L., Chen, X., Cai, Y., Zhang, X., Qian, M., Xingkui, M., Zhao, H., Sheng, M., Cao, G., \& Shen, G. (2020). Removal of veterinary antibiotics from swine wastewater using anaerobic and aerobic biodegradation. Science of the Total Environment, 709, [136094]. https://doi.org/10.1016/j.scitotenv.2019.136094

\section{General rights}

Copyright and moral rights for the publications made accessible in the public portal are retained by the authors and/or other copyright owners and it is a condition of accessing publications that users recognise and abide by the legal requirements associated with these rights.

- Users may download and print one copy of any publication from the public portal for the purpose of private study or research.

- You may not further distribute the material or use it for any profit-making activity or commercial gain

- You may freely distribute the URL identifying the publication in the public portal 


\section{Journal Pre-proof}

Removal of veterinary antibiotics from swine wastewater using anaerobic and aerobic biodegradation

Yuefei Han, Linyan Yang, Xueming Chen, Yu Cai, Xinyue Zhang, Mengcheng Qian, Xingkui Chen, Huihui Zhao, Mei Sheng, Guomin Cao, Genxiang Shen

PII: $\quad$ S0048-9697(19)36090-5

DOI: $\quad$ https://doi.org/10.1016/j.scitotenv.2019.136094

Reference: $\quad$ STOTEN 136094

To appear in: $\quad$ Science of the Total Environment

Received date: $\quad 15$ September 2019

Revised date: $\quad 10$ December 2019

Accepted date: $\quad 10$ December 2019

Please cite this article as: Y. Han, L. Yang, X. Chen, et al., Removal of veterinary antibiotics from swine wastewater using anaerobic and aerobic biodegradation, Science of the Total Environment (2019), https://doi.org/10.1016/j.scitotenv.2019.136094

This is a PDF file of an article that has undergone enhancements after acceptance, such as the addition of a cover page and metadata, and formatting for readability, but it is not yet the definitive version of record. This version will undergo additional copyediting, typesetting and review before it is published in its final form, but we are providing this version to give early visibility of the article. Please note that, during the production process, errors may be discovered which could affect the content, and all legal disclaimers that apply to the journal pertain.

(C) 2019 Published by Elsevier. 


\section{Removal of veterinary antibiotics from swine wastewater using anaerobic and aerobic biodegradation}

Yuefei Han ${ }^{\text {a }}$, Linyan Yang *a,b,c, Xueming Chen ${ }^{\mathrm{d}}$, Yu Cai ${ }^{\mathrm{a}}$, Xinyue Zhang ${ }^{\mathrm{a}}$, Mengcheng Qian $^{\text {a }}$, Xingkui Chen ${ }^{\text {a }}$, Huihui Zhao ${ }^{a}$, Mei Sheng ${ }^{\text {a }}$, Guomin Cao ${ }^{\text {a,b,c }}$, Genxiang Shen ${ }^{\text {e }}$

${ }^{\text {a }}$ School of Resources and Environmental Engineering, East China University of Science and Technology, Shanghai 200237, China

${ }^{\mathrm{b}}$ Shanghai Institute of Pollution Control and Ecological Security, Shanghai 200092, China

${ }^{c}$ National Engineering Laboratory for Industrial Wastewater Treatment, East China University of Science and Technology, Shanghai 200237, China

${ }^{\mathrm{d}}$ Process and Systems Engineering Center (PROSYS), Department of Chemical and Biochemical Engineering, Technical University of Denmark, 2800, Kgs. Lyngby, Denmark

${ }^{\mathrm{e}}$ Shanghai Academy of Environmental Sciences, Shanghai 200233, China

Corresponding Author

*Phone: +86-13270696038; e-mail: lyyang@ecust.edu.cn 


\section{Abstract}

High amounts of antibiotics, used in animal farms for the prevention of diseases, are released back into the natural environment with a possible risk of chronic toxicity to other organisms and the development of antibiotic-resistant genes. The antibiotics, including sulfonamides and $\beta$-lactams, detected in swine wastewater were between 99.2-339.3 $\mu \mathrm{g} / \mathrm{L}$. The typical on-site swine wastewater treatment process turned out to be inadequate, reflected by the high conventional contaminant and antibiotic residuals even under a long hydraulic residence time (HRT, around 2-3 months). The lab-scale combined anaerobic and aerobic biological process showed that anaerobic digestion was mainly responsible for chemical oxygen demand (COD) reduction and aerobic biodegradation contributed significantly to antibiotic removal, with overall removal efficiencies of $95 \%$ for COD and $92 \%$ for antibiotics under a short HRT of 3.3 days. The removal of selected antibiotics could be a combined result of biodegradation, the balance between adsorption and desorption, and the transformation between antibiotic metabolites and their parent antibiotics. The current work provides valuable insights into the appropriate selection and optimisation of biological processes for the treatment of typical wastewater with high COD and trace antibiotics.

Keywords: Antibiotics; Swine wastewater; Anaerobic digestion; Aerobic biodegradation 


\section{Introduction}

Annual antibiotic consumption in China has reached 162,000 tons in 2013, accounting for $\sim 50 \%$ of global usage [1]. Fifty-two percent of the antibiotics are used in animal farms for the prevention and treatment of diseases and to increase production [2-5]. The majority of antibiotics (30\%-90\%), in the form of raw substances or their metabolites, are released back into the natural environment through animal faeces and urine [6-8]. The amount of antibiotics released by animal waste reached 50,000 tons per year [4]. Sulfonamides (SAs) and $\beta$-lactams have been reported as the most widely used antibiotic classes in swine industry and the dominant antibiotic components detected in the swine wastewater [9-12]. The long-term presence of these substances, despite only trace $\mathrm{ng} / \mathrm{L}$ and $\mu \mathrm{g} / \mathrm{L}$ levels in the aquatic environment, may cause chronic toxicity to other organisms and lead to the formation of antibiotic resistance genes (ARGs) [13]. ARGs occur frequently in the effluent of municipal wastewater treatment plants (WWTPs), soils, animal wastes, and even surface water $[1,14]$.

The treatment of antibiotics in animal wastewater is essential for protecting our ecosystem. Animal farms are commonly located far away from the municipal sewage system, which leads to the use of simple treatment units, such as anaerobic digestion (AD), constructed wetlands or lagoons, to treat the animal wastewater $[5,15,16]$. The storage of animal wastewater in a tank for up to several months is also common. These 
treatment processes are easily performed and have relatively low operational and maintenance costs. Nevertheless, they have some significant drawbacks such as 1) a long hydraulic residence time (HRT, corresponding to large disposal facility); 2) climate-dependent treatment efficiency; and 3) a source of contaminants to the surrounding environment. Furthermore, these conventional on-site treatment processes, with the main focus on bulk contaminant removal (e.g. COD), often turn out to be inadequate for the elimination of trace antibiotics in swine wastewater [17]. Other treatment methods, like activated carbon adsorption, membrane filtration, advanced oxidation processes, have been used to remove antibiotics as well [18-22]. However, these advanced treatment methods require complicated pretreatment and post-treatment processes and their costs are relatively high. A cost-effective treatment technique is urgently needed to deal with the substantial amount of animal wastewater that is rich in refractory antibiotics, with the dual consideration of conventional pollutant and antibiotic removal.

A cost-effective biological treatment has been widely used in WWTPs, mainly targeting conventional pollutant removal. Nevertheless, there are only a limited number of existing studies that assess the biological treatment of wastewater, particularly swine wastewater with high COD and trace antibiotics, from the angle of antibiotic removal efficiency. The appropriate selection of biological processes and optimisation of operating conditions is 
of great importance in ensuring effective antibiotic removal from high COD-containing wastewater. The targeted removal efficiency of total antibiotics in swine wastewater is > $60 \%$ when the final effluent is to be reused for irrigation, based on project requirements. An appropriate amount of residual nutrients in the effluent, like nitrogen and phosphorus, is required for plant growth. This study aims to 1) identify the categories and quantities of antibiotics in swine wastewater and evaluate their degradation performance by on-site swine wastewater treatment processes; 2) assess the effectiveness of antibiotic removal by the integrated anaerobic and aerobic biological processes, via altering HRT; and 3) evaluate the respective role of each treatment unit and resolve the possible contaminant degradation mechanisms. The target of antibiotic removal efficiency rather than effluent concentration was set to minimise antibiotic emissions since the discharge standards for individual antibiotics are still unavailable. This study may provide valuable insights into understanding the mechanisms of antibiotic removal by biological treatments and offer information useful for the design or modification of the treatment unit in farms. The scope of this work should be of great interest to both practical and research fields.

\section{Materials and methods}

\subsection{Chemicals and materials}

2.1.1 General chemicals

Hydrochloric acid, sodium hydroxide, sodium thiosulfate, Nessler's reagent, potassium 
sodium tartrate tetrahydrate, sulfamic acid, p-aminobenzene sulfonic acid, ammonium molybdate, amino sulfonic acid, potassium antimony tartrate, potassium persulfate and ascorbic acid were used for the determination of ammonia nitrogen $\left(\mathrm{NH}_{3}-\mathrm{N}\right)$, nitrate nitrogen $\left(\mathrm{NO}_{3}{ }^{-} \mathrm{N}\right)$, nitrite nitrogen $\left(\mathrm{NO}_{2}^{-}-\mathrm{N}\right)$, total phosphorus (TP) and phosphate $\left(\mathrm{PO}_{4}{ }^{3-}-\mathrm{P}\right)$. Ammonium chloride, disodium hydrogen phosphate, glucose and urea were used for the synthetic wastewater preparation (see Supporting Information S1). Sodium carbonate was used for $\mathrm{pH}$ adjustment during biodegradation. Detailed chemical information is listed in Supporting Information S2. Deionized (DI) water was used for all stock solution preparation unless otherwise specified.

Nineteen antibiotics, sulfathiazole (STH), sulfamethazine (SMZ), sulfamethoxazole (SMX), sulfachlorpyridazine (SCP), sulfamethoxypyridazine(SMP), sulfadiazine (SD), sulfamerazine (SMR), sulfamethizole (STZ), trimethoprim (TMP), sulfamethazine (SMT), sulfamonomethoxine (SMM), amoxicillin (AMX), cefpirome sulfate (CPS), procaine penicillin $\mathrm{G}$ (PPG), ampicillin (AMP), ceftiofur (CEF), benzylpenicillin potassium (PCG), cloxacillin sodium (CLX) and benzathine penicillin G (BPG), were analytical grades with $>95 \%$ purity. The first eleven compounds are SAs and the rest are

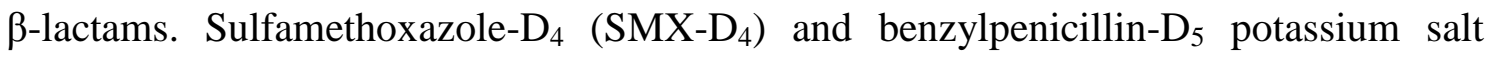
(PCG- $\left.\mathrm{D}_{5}\right)$ were used as internal standards. The detailed information for the antibiotics and internal standards is listed in Supporting Information S3. Sulfuric acid, EDTA-2Na, 
formic acid, methanol, and ethyl acetate were used for the preservation and pretreatment of antibiotic samples. A stock solution containing a mixture of $0.1 \mathrm{~g} / \mathrm{L}$ of each antibiotic was prepared by dissolving the pure chemicals in a mixture of methanol and MilliQ water (Purelab Ultra Analytic) with a volume ratio of 1:1. The stock solution was stored at -20 ${ }^{\circ} \mathrm{C}$ for no more than one month, otherwise, it was re-prepared to eliminate the effect of chemical instability. The antibiotic standards for calibration $(0.004-10 \mu \mathrm{g} / \mathrm{L})$ were obtained by diluting the stock solution with a mixture of methanol and MilliQ water (1:1, v/v) and stored at $4{ }^{\circ} \mathrm{C}$ untill analysis (within 14 days).

\subsubsection{Swine wastewater}

The swine wastewater was collected from a medium-scale swine farm in Shanghai, China, with an annual production of 15,000 pigs. The SAs and $\beta$-lactams (with SMM and SMZ, in particular), as the most widely used antibiotics, were dosed to the swine farm via feed addition and injection. The on-site swine wastewater treatment process is shown in Figure 1. Solid waste is separated by a solid-liquid separation unit and an additional primary sedimentation unit and used as fertilizer. One-third of the wastewater undergoes $\mathrm{AD}$ treatment with an HRT of 53 days (calculated by using the effective reactor volume divided by the influent/effluent volume) and its effluent enters a storage tank. The rest of the wastewater enters the storage tank directly, due to the limited space of the AD tank. The wastewater stays in the storage tank for 90 days, after which the 
effluent, after an appropriate mixing with natural water, is used for irrigation. The swine wastewater in the three sampling points (i.e., AD influent, AD effluent, and storage tank effluent, as shown in Figure 1) was collected in triplicate on August 27 and October 17, 2018, in order to understand the on-site treatment efficiency and the wastewater characteristics at the different times. The collected wastewater samples by $1 \mathrm{~L}$ amber glass bottles were $\mathrm{pH}$ adjusted to 3.0 by $4 \mathrm{M} \mathrm{H}_{2} \mathrm{SO}_{4}$, dosed with methanol $(5 \% \mathrm{v} / \mathrm{v})$ to inhibit microbial activity $[12,23]$, and stored at $4{ }^{\circ} \mathrm{C}$ until antibiotic analysis. The swine wastewater (from AD influent) used for the lab-scale biological experiments was collected separately and was not adjusted.

\subsubsection{Sludge for anaerobic and aerobic degradation}

The anaerobic sludge was collected from an anaerobic reactor in a chemical company in Jiangsu province since on-site anaerobic sludge was unavailable. The aerobic-activated sludge was provided by Shanghai Changqiao municipal WWTP. The sludge was stored at $4{ }^{\circ} \mathrm{C}$ until usage. The mixed liquor suspended solids (MLSS) for anaerobic and aerobic degradation were adjusted to $\sim 16$ and $\sim 3 \mathrm{~g} / \mathrm{L}$ respectively.

\subsection{Anaerobic and aerobic experiments}

The AD experiment was conducted in a glass container with a volume of $1 \mathrm{~L}$, sealed by a rubber plug. A syringe was installed in the plug for sample collection and a headspace 
tube was connected with another container for the release of pressure caused by gas production (Figure 2). The AD reactor was placed in an oscillator (SPH-100C) working at a shaking speed of $150 \mathrm{r} / \mathrm{min}$ and a temperature of $35^{\circ} \mathrm{C}$. The $\mathrm{AD}$ system operated for $21 \mathrm{~h}$ for anaerobic reaction and $2.5 \mathrm{~h}$ for sedimentation. The time for feeding and drainage was $0.5 \mathrm{~h}$. The feeding of swine wastewater (collected from AD influent, $\mathrm{pH}$ adjusted to $8.0 \pm 0.5$ ) was performed via a sampling probe, after which nitrogen was introduced for five minutes to maintain the anaerobic condition with a dissolved oxygen (DO) concentration of less than $0.2 \mathrm{mg} / \mathrm{L}$. The treated swine wastewater was discharged via a siphon. The organic load was enhanced gradually by increasing the feeding volume from 0.1 to $0.3 \mathrm{~L}$ (equivalent to a reduction of HRT from 10 to 3.3 days) with a total running time of 210 days (Table 1), to provide an adaptation process for the sludge, which was originally used for chemical wastewater treatment, and also to evaluate the effect of HRT on degradation performance. The wastewater after AD treatment was collected for COD, nitrogen and phosphorus analysis every two days. The antibiotic samples (in duplicate) were collected for analysis across nine independent days during the AD stabilisation period (after the $120^{\text {th }}$ day).

The aerobic degradation was performed in a sequencing batch reactor (SBR), made of a plexiglass container with an effective volume of $5 \mathrm{~L}$. Uniform aeration by an air pump (ACO-006) with a DO range between $2.0-4.0 \mathrm{mg} / \mathrm{L}$ was performed via an aeration tray 
(HP-60) installed at the bottom of the reactor. The solution $\mathrm{pH}$ was adjusted to $7.0 \pm 0.5$ to sustain the appropriate condition for aerobic biodegradation. The SBR was operated as $21 \mathrm{~h}$ for aerobic reaction, $1 \mathrm{~h}$ for sedimentation and $1.5 \mathrm{~h}$ for resting, under ambient temperature $\left(\sim 25^{\circ} \mathrm{C}\right)$. The time for feeding and drainage was $0.5 \mathrm{~h}$. The synthetic wastewater was fed as a supplement due to the unavailability of real wastewater during the period of 1-28 days. During 29-55 days, 0.3 L swine wastewater from sampling one was used for feeding. Considering the rather high organic content (i.e., COD) in SBR effluent, even under low feeding volume (see more discussion in Section 3.3), the effluent from the laboratory AD reactor was fed to the SBR reactor for the subsequent running process (56-245 days). The feeding volume was increased from 0.3 to $1.5 \mathrm{~L}$ (corresponding to a reduction in HRT from 16.7 to 3.3 days, Table 1) to investigate the effect of HRT on degradation efficiency. The total running time for the SBR was 245 days. The wastewater after aerobic degradation was collected for COD, nitrogen and phosphorus analysis every two days. The antibiotic samples (in duplicate) were collected in three independent days in each period (the $128^{\text {th }}, 136^{\text {th }}$, and $141^{\text {st }}$ days for the period with an HRT of 10 days; the $171^{\text {st }}, 181^{\text {st }}$, and $202^{\text {nd }}$ days for the period with an HRT of 5 days; and the $212^{\text {nd }}, 231^{\text {st }}$, and $243^{\text {rd }}$ days for the period with an HRT of 3.3 days). 


\subsection{Analytical methods}

\subsubsection{General parameters}

The concentrations of $\mathrm{NH}_{3}-\mathrm{N}, \mathrm{NO}_{2}{ }^{-} \mathrm{N}$, and $\mathrm{NO}_{3}{ }^{-}-\mathrm{N}$ were determined by Nessler's reagent spectrophotometry (HJ 535-2009), the spectrophotometric method (GB 7493-87) and ultraviolet spectrophotometry (HJ/T 346-2007), respectively. Samples for COD and TN determination were digested via Digital Reactor Block 200 and analysed by DR 3900 spectrophotometer (Hach, USA). TP was measured by the ammonium molybdate spectrophotometric method (GB 11893-89). The calcium and magnesium elements were determined by atomic absorption spectroscopy (AAS, novAA400, JENA). The DO and $\mathrm{pH}$ were monitored by portable DO (HACH, HQ40d) and pH meters (FE20 Plus), respectively. The MLSS was determined using the gravimetric method [24].

\subsubsection{Antibiotic quantification}

The sample for antibiotic determination was centrifuged in a glass centrifuge tube at 3000 r/min for five minutes and filtered by a $0.7 \mu \mathrm{m}$ glass fibre membrane (Whatman GF/F). The $50 \mathrm{~mL}$ filtrated sample was diluted 10 times with MilliQ water to enhance the subsequent extraction efficiency. The increase of sample volume was equivalent to the increase of contact time between antibiotics and adsorbents. The $0.2 \mathrm{~g}$ EDTA-2Na was added to the diluted sample to coordinate the multivalent cations (e.g., calcium) which might affect the antibiotic determination [25]. The $\mathrm{pH}$ was adjusted to 3.0 by $2.5 \mathrm{M}$ $\mathrm{H}_{2} \mathrm{SO}_{4}$. The $\mathrm{SMX}-\mathrm{D}_{4}$ and PCG-D $\mathrm{D}_{5}$ of $100 \mathrm{ng}$ each were added into the sample as internal 
standards. The solid-phase extraction cartridges (CNW Poly-Sery HLB, 500 mg, 6 mL) were preconditioned in an order with $5 \mathrm{~mL}$ ethyl acetate, $5 \mathrm{~mL}$ methanol and $5 \mathrm{~mL}$ MilliQ water (pH 3.0). The sample was subsequently introduced to the cartridge at a flow rate of 3-5 $\mathrm{mL} / \mathrm{min}$. The inner wall of sample container was washed with $10 \mathrm{~mL}$ MilliQ water ( $\mathrm{pH}$ 3.0), which was introduced into the cartridge followed by 30 minutes of vacuum pumping. The impurity in the cartridge was washed by $5 \mathrm{~mL}$ MilliQ water with $5 \%$ methanol and $5 \mathrm{~mL}$ MilliQ water ( $\mathrm{pH} 3.0)$, followed by 10 minutes of vacuum drying. The antibiotics retained on the cartridges were eluted with methanol alone $(5 \mathrm{~mL})$ and subsequently a mixture of methanol and ethyl acetate $(1: 1, \mathrm{v} / \mathrm{v}, 5 \mathrm{~mL})$. The eluate was evaporated by a gentle stream of nitrogen at $15 \mathrm{~L} / \mathrm{min}$ in a water bath at $35^{\circ} \mathrm{C}$. The $1 \mathrm{~mL}$ mixture of methanol and MilliQ water $(1: 1, \mathrm{v} / \mathrm{v})$ was added slowly along the tube wall, followed by 5 minutes of ultrasonication via an ultrasonic cleaner (KQ-100V, 40KHz) to enhance antibiotic dissolving. The extract was further filtered via a $0.22 \mu \mathrm{m}$ PTFE filter (Anpel, China) and was ready for antibiotic analysis.

The antibiotics were analysed using a liquid chromatography-tandem mass spectrometry (LC-MS/MS, LC-30A, LCMS-8050, Shimadzu) coupled with a Shim-pack GISS C18 column (100 mmLx 2.1 mmI.D., $1.9 \mu \mathrm{m}, \mathrm{P} / \mathrm{N}$ : 227-30048-02, Shimadzu). The $2 \mu \mathrm{L}$ sample was injected with the freshly prepared mobile phase as a combination of solution A (MilliQ water with $0.1 \%$ formic acid) and B (methanol) at a total flow rate of 0.4 
$\mathrm{mL} / \mathrm{min}$. The mobile phase program, which took a total of 10 minutes to run, was controlled as follows: 1) hold $10 \%$ solution B (the rest $90 \%$ was solution A) for 0.2 minutes, 2) increase gradually to $25 \%$ until 1 minute, 3 ) increase gradually to $30 \%$ until 4 minutes, 4) increase gradually to $80 \%$ until 4.5 minutes and hold for 2.5 minutes, and 5) hold $10 \%$ for 3 minutes for column equilibration. The column temperature was kept at $40{ }^{\circ} \mathrm{C}$. The MS system was equipped with an electrospray ionisation source and operated in a positive ion mode; except for the determination of BPG. The method development and validation parameters with retention time, precursor and product ions, linearity, limit of detection (LOD) and limit of quantification (LOQ) are listed in detail in Supporting Information S4.

\subsection{Statistical methods}

One-way analysis of variance (ANOVA) was used to compare the impact of different wastewater treatment methods and antibiotic concentrations during different periods. The specified level of type I error $\alpha$ is equal to 0.05 , indicating that $p \leq 0.05$ means the difference is significant.

\section{Results and discussion}

\subsection{On-site swine wastewater treatment}

The characteristics of the swine wastewater collected at the three different locations are 
shown in Table 2. The swine wastewater after primary sedimentation still had substantial organic and nutrient content, with COD, TN and TP concentrations of 5683, 865 and $52 \mathrm{mg} / \mathrm{L}$, respectively. The $\mathrm{NH}_{3}-\mathrm{N}$ and $\mathrm{PO}_{4}{ }^{3-}-\mathrm{P}$ as the main components, accounted for $97 \%$ and $85 \%$ of $\mathrm{TN}$ and $\mathrm{TP}$, respectively. After $\mathrm{AD}$ treatment, a significant proportion of these substances was removed, with removal efficiencies of $81 \%$ and $62 \%$ for COD and TP, respectively (calculated by the concentrations of samples collected in AD influent and effluent, as shown in Table 2). Only $21 \%$ of TN was removed since the anaerobic conditions were unsuitable for nitrification (as a major mechanism for the removal of the abundant $\mathrm{NH}_{3}-\mathrm{N}$ ). The removal of TN and TP might be attributed to the formation of struvite, calcium phosphate and other potential precipitations as a result of the abundant presence of calcium $(95 \mathrm{mg} / \mathrm{L})$ and magnesium $(57 \mathrm{mg} / \mathrm{L})$ in swine wastewater. The significant decrease of calcium and magnesium concentrations to 26 and $34 \mathrm{mg} / \mathrm{L}$, respectively, in the AD effluent further verified our assumption. In addition, we observed a significant number of crystals deposited on the wall of the container (see Supporting Information S5). The formation of phosphine may contribute to phosphorus removal under $\mathrm{AD}$ conditions as well $[26,27]$. The regular cleaning of pipelines and devices is highly recommended to prevent deposition and scaling issues. Treatment efficiencies of $84 \%$ for $\mathrm{COD}, 17 \%$ for $\mathrm{TN}$ and $35 \%$ for $\mathrm{TP}$ for the storage tank were calculated based on the data from the three sampling points. For example, based on COD concentrations (i.e., 5683, 1097 and $657 \mathrm{mg} / \mathrm{L}$ for AD influent, 
AD effluent and storage tank effluent, respectively, see Table 2) and the split-flow (as only one-third of wastewater underwent AD treatment, see Figure 1), the COD removal efficiency was calculated as $1-\frac{657}{5683 \times \frac{2}{3}+1097 \times \frac{1}{3}}=84 \%$. The residual COD was within the range of $560-752 \mathrm{mg} / \mathrm{L}$, which was significantly higher than the maximum contaminant level $(\mathrm{MCL}=200 \mathrm{mg} / \mathrm{L})$ permitted by Irrigation Water Quality Standards (GB 5048-2005). Further treatment is therefore needed to ensure the discharge is within acceptable levels.

The total amount of antibiotics in AD influent on August 23, 2018 was $99.2 \mu \mathrm{g} / \mathrm{L}$, of which $98 \%$ were SMM (Figure 3a). The SMM concentration of $97.6 \mu \mathrm{g} / \mathrm{L}$ was within the range of $23-134 \mu \mathrm{g} / \mathrm{L}$ reported by other researchers [12]. The high concentration of SMM is a result of its universal use, due to its high efficacy, easy dissolution, and low acetylation rate. The other SAs were present with $\mathrm{ng} / \mathrm{L}$ levels, following a decreasing order of SMZ, STH, SD, SCP, SMP and SMX 276, 134, 126, 85, 53 and $18 \mathrm{ng} / \mathrm{L}$, respectively. The $\beta$-lactams also existed at trace levels: CLX, BPG, PCG, AMP, AMX, CEF and PPG had levels of 339, 190, 156, 75, 60, 51 and $35 \mathrm{ng} / \mathrm{L}$, respectively. Other researchers similarly found that $\beta$-lactams have relatively low concentrations or are even undetectable due to their hydrolysable character [28, 29]. The other antibiotics, SMR, STZ, SMT, TMP and CPS, were not detectable $(<4 \mathrm{ng} / \mathrm{L})$. AD treatment reduced the total amount of antibiotics to $11.3 \mu \mathrm{g} / \mathrm{L}$, of which SMM was still the predominant 
compound. After 90 days of natural degradation in the storage tank, $73 \%$ of the total antibiotics were further removed. At this point, SMZ exceeded SMM (14.2 vs. $4.3 \mu \mathrm{g} / \mathrm{L})$ becoming the most abundant antibiotic.

The overall removal efficiency of antibiotics was $81 \%$ after the on-site swine wastewater treatment (Figure 3b). Individual antibiotics, including SMM, CLX, PCG, CEF, SMT, SD, BPG, SMP and STH, were better eliminated by the storage tank than AD. Notably, the concentrations of some antibiotics, particularly SAs (e.g., SMZ and SMX), increased after AD or storage tank treatment (corresponding to negative removal efficiencies). The possible reason is that the analytically-camouflaged antibiotic metabolites are conversed back to their detectable parent antibiotics, triggered by a complicated evolutionary process $[2,30,31]$. For example, SMZ in the storage tank effluent was significantly higher than that in AD influent (14.2 vs. $0.3 \mu \mathrm{g} / \mathrm{L}, p \leq 0.05$, ANOVA), which might be a result of the transformation of glucuronide of $\mathrm{N}$-4-acetylated sulfamethazine (a metabolite of SMZ) to their parent SMZ in the liquid phase [32]. SMZ in animal bodies tends to bind with carbohydrates and reverses to its original form in a period after excretion due to the rapid biodegradation of carbohydrates in the natural environment [33]. Similarly, 53-68\% of SMX was excreted from the animals in the form of transformed SMX [34], which may transfer back to SMX molecules during the wastewater treatment process [35]. Another possible reason 
is that the antibiotics originally absorbed on the surface of the suspended solids (with total suspended solids of $5.45 \mathrm{~g} / \mathrm{L}$ ) in swine wastewater dissolved back to the aqueous phases during the reaction process [10].

The total antibiotic concentration on October 17 was significantly higher compared to that on August 23 (339.3 v.s. $99.2 \mu \mathrm{g} / \mathrm{L}, p \leq 0.05$, ANOVA, Figure 3c). More types of antibiotics, including TMP, STZ and SMR, occurred in the AD influent. The concentrations of some antibiotics (SMZ, SCP, AMX, CLX, and SMX) in the AD influent more than doubled. However, AMP and CEF were no longer detectable. The different types and amounts of antibiotics used to deal with different swine diseases during the various periods could be partially responsible for this diversity. The drug usage records in the farm show that the average antibiotic dosage in October was doubled that of August over the past four years. The antibiotics in the storage tank effluent were dominated by SMM $(12.9 \mu \mathrm{g} / \mathrm{L})$ and SMZ $(7.6 \mu \mathrm{g} / \mathrm{L})$. The total residual antibiotic concentrations after the on-site swine wastewater treatment were comparable in across the two sampling dates $(\sim 20 \mu \mathrm{g} / \mathrm{L})$. For most individual antibiotics, AD showed better removal efficiencies than the storage tank in October, in contrast to the observation in August. The lower temperature in mid-October $\left(<15^{\circ} \mathrm{C}\right)$ may restrain the treatment efficiency of the outdoor storage tank, while its effect on the sealed AD unit might be negligible. The fact that the residual antibiotic and COD concentrations 
were still high after the on-site wastewater treatment process, even under an HRT as high as $2-3$ months, triggered the subsequent exploration of a more effective process for swine wastewater treatment.

\subsection{Performance of anaerobic digestion}

The COD removal efficiency did not show any significant difference with the gradual decrease of HRT from 10 to 3.3 days in the AD unit (Figure 4a). The variance for the effluent COD concentration seemed to be caused solely by the influent COD concentration. For example, the sharp increase of influent COD from $\sim 1750$ to $\sim 4000$ $\mathrm{mg} / \mathrm{L}$ at around the $150^{\text {th }}$ day resulted in the effluent concentration increasing from $\sim 1500$ to $\sim 3000 \mathrm{mg} / \mathrm{L}$. The average COD removal efficiency was $43 \%$. AD showed a poor $\mathrm{TN}$ degradation performance throughout the entire reaction process (Figure $4 \mathrm{~b}$ ). The majority of $\mathrm{TN}$ in $\mathrm{AD}$ effluent was still $\mathrm{NH}_{3}-\mathrm{N}(93 \%)$ and nitrogen oxides (the summation of $\mathrm{NO}_{2}-\mathrm{N}$ and $\mathrm{NO}_{3}-\mathrm{N}$ ) were less than $20 \mathrm{mg} / \mathrm{L}$. The TP removal efficiency was $29 \%$, possibly caused by precipitation and evaporation (e.g., struvite and phosphine).

Only $3 \%$ of the total antibiotics were removed by the AD unit on the $120^{\text {th }}$ day (Figure 5). A low degradation efficiency was also observed in other intermittent sampling days (Supporting Information S6). Recent studies have demonstrated that AD is limited in its 
ability to removal antibiotics from wastewater [10, 12, 36, 37]. Antibiotics, particularly SAs, containing aromatic rings and double bond functional groups are robust and have high resistance to biodegradation [2]. However, some individual trace SAs still had relatively high removal efficiency, for instance, $85 \%$ for SMP, 97\% for SCP and $88 \%$ for SMX. The presence of nitrogen and sulphur in the molecular structures of some SAs might enhance anaerobic degradation $[10,38]$. The different reduction potential may also affect degradation performance. For instance, SMX needs a lower reduction potential than SMZ in the initiation of an ipso-hydroxylation with subsequent fragmentation, which is a common degradation pathway for SAs $[38,39]$. The $\beta$-lactams seemed more anaerobic degradable than SAs, reflected in total removal efficiencies of $69 \%$ for $\beta$-lactams and $2 \%$ for SAs. The removal efficiency of individual $\beta$-lactams followed a decreasing order of $\operatorname{CLX}(97 \%)>\operatorname{CEF}(83 \%) \approx \mathrm{AMP}(83 \%)>\mathrm{BPG}(77 \%)>\mathrm{AMX}$ $(57 \%)>$ PCG $(17 \%)>$ PPG $(0.5 \%)$. The negative removal efficiencies for SD, SMZ, and STH were the same as those observed in the on-site AD treatment (Section 3).

Following the increase of feedwater antibiotic concentration to $\sim 340 \mu \mathrm{g} / \mathrm{L}$ on the $172^{\text {nd }}$ day (the feedwater was collected on October 17, 2018), effluent concentration increased within 10 days (see Supporting Information S6). A notable antibiotic reduction was subsequently observed, indicating the potential enhancement of antibiotic degradation by extending the $\mathrm{AD}$ operation time. The higher influent antibiotic concentration 
corresponding to better degradation efficiency, may be attributed to its comparative advantage over the conventional organic substances for biodegradation [36].

The lab-scale AD effluent (with $1172 \mathrm{mg} / \mathrm{L} \mathrm{COD,} 848 \mathrm{mg} / \mathrm{L} \mathrm{NH}_{3}-\mathrm{N}$ and $19 \mathrm{mg} / \mathrm{L} \mathrm{TP}$ ) had a comparable organic and nutrient content to the on-site AD effluent, although HRT was shortened from 53 to 3.3 days. However, the overall antibiotic degradation in this lab-scale AD unit was much poorer compared to the on-site AD treatment (3\% vs. $89 \%$ ). It seems that the extension of $\mathrm{AD}$ operation time may potentially enhance degradation performance, while extremely long-term inoculation seems impractical in a farm [36]. A fast and efficient treatment method is needed further to achieve better water quality.

\subsection{Performance of aerobic degradation}

Conventional parameters including COD, nitrogen and phosphorus were continuously monitored to assess the SBR performance. The COD removal efficiency increased gradually from $\sim 50 \%$ to $80 \%$ in the first 28 days with synthetic wastewater as feedwater (Figure 6a). The easily degradable glucose, as the main organic component of synthetic wastewater (Supporting Information S1), resulted in a high COD removal efficiency. The COD in the effluent reached as high as $\sim 600 \mathrm{mg} / \mathrm{L}$ once the swine wastewater was available (29-55 days), although only $0.3 \mathrm{~L}$ was fed to the reactor. In consideration of the presence of the $\mathrm{AD}$ unit in the on-site treatment system, the lab-scale AD effluent 
was subsequently fed to the SBR with a gradual increase of feedwater volume from 0.3

to $1.5 \mathrm{~L}$. The effluent COD concentrations remained within $\sim 200-400 \mathrm{mg} / \mathrm{L}$ despite the significant fluctuations of feedwater COD concentrations $(\sim 200-800 \mathrm{mg} / \mathrm{L})$. The sludge seemed to be well inoculated, reflected in increased COD removal efficiencies from $18 \%$ to $58 \%$ and the gradual growing of MLSS from 3.5 to $7.2 \mathrm{~g} / \mathrm{L}$ (Table 1).

The TN removal was not obvious in the entire SBR running process, except between the $29^{\text {th }}$ and $55^{\text {th }}$ days (Figure 6 b). The denitrification effect should be responsible for the TN decline. It was not uncommon to observe the solution DO as low as $0.5 \mathrm{mg} / \mathrm{L}$, especially within two hours after wastewater feeding. This short-term anoxic environment may allow the survival of heterotrophic denitrifying bacteria, with the aid of easily degradable glucose residuals in the reactor. Upon the change of the feedwater type and volume, a small portion of $\mathrm{NH}_{3}-\mathrm{N}$ remained in the reactor for a period and subsequently almost completely converted to $\mathrm{NO}_{3}{ }^{-} \mathrm{-N}$ under aerobic conditions (29-55 days, Figure 6c). The $\mathrm{NO}_{2}^{-}-\mathrm{N}$ up to $\sim 300 \mathrm{mg} / \mathrm{L}$ was accumulated between the $29^{\text {th }}$ and $55^{\text {th }}$ days. The sharp $\mathrm{pH}$ decline during the reaction, from 7.8 to 5.5 , caused by the nitrification process, might be responsible for the deteriorated $\mathrm{NO}_{2}{ }^{-} \mathrm{N}$ transformation, since an excess of hydrogen ions may inhibit the growth of nitrite-oxidizing bacteria (NOB) [40]. The $\mathrm{pH}$ was adjusted to $7.0 \pm 0.5$ by sodium carbonate in the subsequent running process and $\mathrm{NO}_{2}{ }^{-} \mathrm{N}$ was no longer accumulated. In addition, the competition 
for oxygen utilisation between NOB for nitrification and microbes for COD degradation may contribute to $\mathrm{NO}_{2}{ }^{-} \mathrm{N}$ accumulation, since the influent $\mathrm{COD}$ was the highest between the $29^{\text {th }}$ and $55^{\text {th }}$ days than in other periods [40]. The $\mathrm{NO}_{2}^{-}-\mathrm{N}$ accumulation may also be associated with trace antibiotics [41].

The total amount of antibiotics in the SBR effluent were 3.1, 18.9 and $27.7 \mu \mathrm{g} / \mathrm{L}$ for the running periods, with HRTs of 10, 5 and 3.3 days, respectively (Figure 7a). Four SAs were detectable during the period with an HRT of 10 days, following a decreasing order: $\operatorname{SMM}(2.1 \mu \mathrm{g} / \mathrm{L})>\mathrm{SD}(290 \mathrm{ng} / \mathrm{L})>\mathrm{SCP}(75 \mathrm{ng} / \mathrm{L})>\mathrm{STH}(9 \mathrm{ng} / \mathrm{L})$. CEF $(3 \mathrm{ng} / \mathrm{L})$ was the only detectable $\beta$-lactam. With the increase of feedwater volume from 0.5 to $1.5 \mathrm{~L}$, all of the individual antibiotic concentrations increased, except SMX which decreased. The gradual growth of MLSS (from 4.1 to $7.2 \mathrm{~g} / \mathrm{L}$, Table 1) might contribute to the substantial SMX removal because of its high adsorption capacity in the activated sludge $[36,42]$. The effluent concentrations of SMZ, AMX, SMR and TMP during the period with an HRT of 3.3 days were several times higher than the previous periods, demonstrating that an increase in organic load may have a negative impact on antibiotic removal $[43,44]$.

The overall removal efficiency of the antibiotics by aerobic treatment was $93 \%$, significantly higher than that of AD treatment with a removal efficiency of $3 \%(p \leq 0.05$, ANOVA). Other researchers have similarly found that the majority of antibiotics are 
removed (71-85\%) under aerobic conditions, while only a small portion (of 7-23\%) are removed under anoxic conditions [18]. Figure $7 \mathrm{~b}$ shows the antibiotic removal efficiencies in the three independent sampling dates for each period. The average removal efficiencies decreased from $97 \%$ to $89 \%$ when the HRT decreased from 10 to 3.3 days, while the COD removal efficiencies showed the opposite trend (Figure 6a). The competitive advantage of COD over antibiotics was more obvious when the influent COD concentration was higher between the $204^{\mathrm{h}}$ and $245^{\text {th }}$ days. The microorganisms tend to utilise the easily degradable conventional organic substances, rather than the refractory antibiotics, to maintain their survival and metabolism [36, 43]. The SAs seemed more degradable than $\beta$-lactams under aerobic conditions. SAs are more adaptable to the biodegradation environment and are involved in co-metabolic processes [44-46].

\subsection{Implications}

This study assessed antibiotic degradation performance in a full-scale on-site swine wastewater treatment process. The long HRT (corresponding to a larger disposal facility), and high COD and antibiotic concentrations in the effluent triggered the investigation of an alternative treatment process, the combined anaerobic and aerobic biological process, at lab-scale. Overall removal efficiencies of $92 \%$ for antibiotics (higher than our target of $60 \%$, mainly attributed by aerobic biodegradation) and 95\% for COD (mainly attributed 
to $\mathrm{AD})$ were achieved with an HRT of 3.3 days after integrated anaerobic and aerobic treatment. The substantial removal of COD by the anaerobic treatment unit could reduce the organic load (corresponding to lower treatment cost) and thereby enhance the competitive role of antibiotics over COD for degradation (corresponding to higher antibiotic removal efficiency) for the downstream aerobic treatment unit. The system effluent, with an adequate amount of nutrients (TN and TP), is supposed to be reused for irrigation purpose. This combined process is, therefore, more cost-effective than the commonly used single anaerobic or aerobic unit. The scope of this work related to the evaluation of the combined anaerobic and aerobic biological process, and the optimisation of operation conditions (i.e., HRT) should be of great interest to both research and practical fields. Nevertheless, the best operation for anaerobic and aerobic processes should not be limited to HRT control. Our further study will focus on the optimisation of other operation conditions (e.g., sludge residence time, solution $\mathrm{pH}$, aeration time) in order to achieve better performance. Besides, the identification of microbes responsible for the degradation of specific antibiotics is crucial for the effective control of the biological process.

\section{Conclusions}

In this study, we investigated the occurrence of nineteen antibiotics in swine wastewater.

The total antibiotic concentrations fluctuated from 99.2 to $339.3 \mu \mathrm{g} / \mathrm{L}$ (of which $98 \%$ 
were SMM), possibly because the varied incidence and types of swine disease in different periods resulted in the use of different types and amount of antibiotics. The long HRT and high residual contaminants demonstrated that the on-site treatment process ( $\mathrm{AD}$ followed by the storage tank) was insufficient or unsuitable for swine wastewater treatment. Therefore, lab-scale combined anaerobic and aerobic processes for swine wastewater treatment were systematically investigated. The AD unit demonstrated higher COD than antibiotic removal (43\% v.s. $3 \%)$. The aerobic treatment contributed significantly to antibiotic degradation. The overall removal efficiencies reached $95 \%$ for COD and $92 \%$ for antibiotics during the integrated biological process operated under an HRT as low as 3.3 days. The treated wastewater, with an appropriate mixing with natural water, could be reused for irrigation.

\section{Acknowledgements}

This study was supported by National Water Pollution Control and Treatment Science and Technology Major Project (2017ZX07207002). The authors are grateful to the State Environmental Protection Key Laboratory of Environmental Risk Assessment and Control on Chemical Process in East China University of Science and Technology for the antibiotic analysis by LC-MS/MS.

\section{Declarations of interest: none}




\section{References}

[1] M. Qiao, G.-G. Ying, A.C. Singer, Y.-G. Zhu, Review of antibiotic resistance in

China and its environment, Environ. Int., 110 (2018) 160-172.

[2] A.K. Sarmah, M.T. Meyer, A.B.A. Boxall, A global perspective on the use, sales, exposure pathways, occurrence, fate and effects of veterinary antibiotics (VAs) in the environment, Chemosphere, 65 (2006) 725-759.

[3] M.D. Barton, Impact of antibiotic use in the swine industry, Curr. Opin. Microbiol., 19 (2014) 9-15.

[4] Q.-Q. Zhang, G.-G. Ying, C.-G. Pan, Y.-S. Liu, J.-L. Zhao, Comprehensive Evaluation of Antibiotics Emission and Fate in the River Basins of China: Source Analysis, Multimedia Modeling, and Linkage to Bacterial Resistance, Environ. Sci. Technol., 49 (2015) 6772-6782.

[5] R. Wang, F. Feng, Y. Chai, X. Meng, Q. Sui, M. Chen, Y. Wei, K. Qi, Screening and quantitation of residual antibiotics in two different swine wastewater treatment systems during warm and cold seasons, Sci. Total Environ., 660 (2019) 1542-1554.

[6] S. Kuppusamy, D. Kakarla, K. Venkateswarlu, M. Megharaj, Y.-E. Yoon, Y.B. Lee, Veterinary antibiotics (VAs) contamination as a global agro-ecological issue: A critical view, Agriculture Ecosystems \& Environment, 257 (2018) 47-59.

[7] J. Chen, Y.-S. Liu, J.-N. Zhang, Y.-Q. Yang, L.-X. Hu, Y.-Y. Yang, J.-L. Zhao, F.-R. Chen, G.-G. Ying, Removal of antibiotics from piggery wastewater by biological 
aerated filter system: Treatment efficiency and biodegradation kinetics, Bioresour. Technol., 238 (2017) 70-77.

[8] J. Lienert, K. Gudel, B.I. Escher, Screening method for ecotoxicological hazard assessment of 42 pharmaceuticals considering human metabolism and excretory routes, Environ. Sci. Technol., 41 (2007) 4471-4478.

[9] J. Cha, K.H. Carlson, Occurrence of ss-lactam and polyether ionophore antibiotics in lagoon water and animal manure, Sci. Total Environ., 640 (2018) 1346-1353.

[10] Y. Chen, H. Zhang, Y. Luo, J. Song, Occurrence and dissipation of veterinary antibiotics in two typical swine wastewater treatment systems in east China, Environ. Monit. Assess., 184 (2012) 2205-2217.

[11] J. Wang, W. Ben, M. Yang, Y. Zhang, Z. Qiang, Dissemination of veterinary antibiotics and corresponding resistance genes from a concentrated swine feedlot along the waste treatment paths, Environ. Int., 92-93 (2016) 317-323.

[12] M. Zhang, Y.-S. Liu, J.-L. Zhao, W.-R. Liu, L.-Y. He, J.-N. Zhang, J. Chen, L.-K. He, Q.-Q. Zhang, G.-G. Ying, Occurrence, fate and mass loadings of antibiotics in two swine wastewater treatment systems, Sci. Total Environ., 639 (2018) 1421-1431.

[13] M. Adeel, X. Song, Y. Wang, D. Francis, Y. Yang, Environmental impact of estrogens on human, animal and plant life: A critical review, Environ. Int., 99 (2017) 107-119.

[14] S. Jia, X.-X. Zhang, Y. Miao, Y. Zhao, L. Ye, B. Li, T. Zhang, Fate of antibiotic 
resistance genes and their associations with bacterial community in livestock breeding wastewater and its receiving river water, Water Res., 124 (2017) 259-268.

[15] L. Liu, C. Liu, J. Zheng, X. Huang, Z. Wang, Y. Liu, G. Zhu, Elimination of veterinary antibiotics and antibiotic resistance genes from swine wastewater in the vertical flow constructed wetlands, Chemosphere, 91 (2013) 1088-1093.

[16] D.L. Cheng, H.H. Ngo, W.S. Guo, Y.W. Liu, J.L. Zhou, S.W. Chang, D.D. Nguyen, X.T. Bui, X.B. Zhang, Bioprocessing for elimination antibiotics and hormones from swine wastewater, Sci. Total Environ., 621 (2018) 1664-1682.

[17] L.-J. Zhou, G.-G. Ying, R.-Q. Zhang, S. Liu, H.-J. Lai, Z.-F. Chen, B. Yang, J.-L. Zhao, Use patterns, excretion masses and contamination profiles of antibiotics in a typical swine farm, south China, Environmental Science-Processes \& Impacts, 15 (2013) 802-813.

[18] W. Zhao, Q. Sui, X. Mei, X. Cheng, Efficient elimination of sulfonamides by an anaerobic/anoxic/oxic-membrane bioreactor process: Performance and influence of redox condition, Sci. Total Environ., 633 (2018) 668-676.

[19] P. Liu, H. Zhang, Y. Feng, F. Yang, J. Zhang, Removal of trace antibiotics from wastewater: A systematic study of nanofiltration combined with ozone-based advanced oxidation processes, Chem. Eng. J., 240 (2014) 211-220.

[20] F. Yu, Y. Li, S. Han, J. Ma, Adsorptive removal of antibiotics from aqueous solution using carbon materials, Chemosphere, 153 (2016) 365-385. 
[21] J. Wang, R. Zhuan, L. Chu, The occurrence, distribution and degradation of antibiotics by ionizing radiation: An overview, Sci. Total Environ., 646 (2019) $1385-1397$.

[22] V. Homem, L. Santos, Degradation and removal methods of antibiotics from aqueous matrices - A review, J. Environ. Manage., 92 (2011) 2304-2347.

[23] L.J. Zhou, G.-G. Ying, S. Liu, J.-L. Zhao, F. Chen, R.-Q. Zhang, F.-Q. Peng, Q.-Q. Zhang, Simultaneous determination of human and veterinary antibiotics in various environmental matrices by rapid resolution liquid chromatography-electrospray ionization tandem mass spectrometry, J. Chromatogr., 1244 (2012) 123-128.

[24] APHA, Standard Methods for the Examination of Water and Wastewater, American Public Health Association (APHA), Washington, DC, USA (2005), (2005).

[25] L.-J. Zhou, G.-G. Ying, S. Liu, J.-L. Zhao, F. Chen, R.-Q. Zhang, F.-Q. Peng, Q.-Q. Zhang, Simultaneous determination of human and veterinary antibiotics in various environmental matrices by rapid resolution liquid chromatography-electrospray ionization tandem mass spectrometry, J. Chromatogr., 1244 (2012) 123-138.

[26] M. Lu, X. Niu, W. Chen, Z. Liang, S. You, X. Gu, Phosphine production in anaerobic wastewater treatment under tetracycline antibiotic pressure, Journal of Environmental Sciences, 69 (2018) 239-250.

[27] F. Eismann, D. Glindemann, A. Bergmann, P. Kuschk, Effect of free phosphine on anaerobic digestion, Water Res., 31 (1997) 2771-2774. 
[28] T.V.d. Meersche, E.V. Pamel, C.V. Poucke, L. Herman, M. Heyndrickx, G. Rasschaert, E. Daeseleire, Development, validation and application of an ultra high performance liquid chromatographic-tandem mass spectrometric method for the simultaneous detection and quantification of five different classes of veterinary antibiotics in swine manure, J. Chromatogr., 1429 (2016) 248-257.

[29] B.J.A. Berendsen, M.L. Essers, P.P.J. Mulder, G.D.v. Bruchem, A. Lommen, W.M.v. Overbeek, L.A.M. Stolker, Newly identified degradation products of ceftiofur and cephapirin impact the analytical approach for quantitative analysis of kidney, J. Chromatogr., 1216 (2009) 8177-8186.

[30] T. Christian, R.J. Schneider, H.A. Farber, D. Skutlarek, M.T. Meyer, H.E. Goldbach, Determination of antibiotic residues in manure, soil, and surface waters, Acta Hydrochim. Hydrobiol., 31 (2003) 36-44.

[31] N. Kemper, Veterinary antibiotics in the aquatic and terrestrial environment, Ecol. Indicators, 8 (2008) 1-13.

[32] K. Berger, B. Petersen, H. Buning-Pfaue, Persistence of drugs occurring in liquid manure in the food chain[PERSISTENZ VON GULLE-ARZNEISTOFFEN IN DER NAHRUNGSKETTE], Archiv fur Lebensmittelhygiene, 37 (1986) 99-102.

[33] R. Rebecca, Do cattle growth hormones pose an environmental risk?, Environ. Sci. Technol., 36 (2002) 194A.

[34] A.J.A.M. Van Der Ven, T.B. Vree, E.W.J. Van Ewijk-Beneken Kolmer, P.P. 
Koopmans, J.W.M. Van Der Meer, Urinary recovery and kinetics of sulphamethoxazole and its metabolites in HIV-seropositive patients and healthy volunteers after a single oral dose of sulphamethoxazole, Br. J. Clin. Pharmacol., 39 (1995) 621-625.

[35] A. Gobel, A. Thomsen, C.S. McArdell, A. Joss, W. Giger, Occurrence and sorption behavior of sulfonamides, macrolides, and trimethoprim in activated sludge treatment, Environ. Sci. Technol., 39 (2005) 3981-3989.

[36] W. Zheng, Z. Zhang, R. Liu, Z. Lei, Removal of veterinary antibiotics from anaerobically digested swine wastewater using an intermittently aerated sequencing batch reactor, Journal of Environmental Sciences, 65 (2018) 8-17.

[37] P. Zhou, C.Y. Su, B.W. Li, Q. Yi, Treatment of high-strength pharmaceutical wastewater and removal of antibiotics in anaerobic and aerobic biological treatment processes, Journal Of Environmental Engineering-Asce, 132 (2006) 129-136.

[38] K.C. Wijekoon, J.A. McDonald, S.J. Khan, F.I. Hai, W.E. Price, L.D. Nghiem, Development of a predictive framework to assess the removal of trace organic chemicals by anaerobic membrane bioreactor, Bioresour. Technol., 189 (2015) 391-398.

[39] B. Ricken, P.F.X. Corvini, D. Cichocka, M. Parisi, M. Lenz, D. Wyss, P.M. Martinez-Lavanchy, J.A. Mueller, P. Shahgaldian, L.G. Tulli, H.-P.E. Kohler, B.A. Kolvenbach, ipso-Hydroxylation and Subsequent Fragmentation: a Novel Microbial Strategy To Eliminate Sulfonamide Antibiotics, Appl. Environ. Microbiol., 79 (2013) $5550-5558$. 
[40] L. Yang, A. Giannis, V.W.C. Chang, B. Liu, J. Zhang, J.-Y. Wang, Application of hydroponic systems for the treatment of source-separated human urine, Ecol. Eng., 81 (2015) 182-191.

[41] M. Huang, B. Xiao, W. Zhang, Z. Huang, L. Chen, D. Chen, Removal performance and changes in the microbial communities of SBRs under aerobic and anoxic conditions with trace tetracycline pressure, Journal of Environmental Science and Health Part a-Toxic/Hazardous Substances \& Environmental Engineering, 49 (2014) 940-947.

[42] W. Ben, Z. Qiang, X. Yin, J. Qu, X. Pan, Adsorption behavior of sulfamethazine in an activated sludge process treating swine wastewater, Journal of Environmental Sciences, 26 (2014) 1623-1629.

[43] E.J. McAdam, J.P. Bagnall, A. Soares, Y.K.K. Koh, T.Y. Chiu, M.D. Scrimshaw, J.N. Lester, E. Cartmell, Fate of Alkylphenolic Compounds during Activated Sludge Treatment: Impact of Loading and Organic Composition, Environ. Sci. Technol., 45 (2011) 248-254.

[44] T. Ngoc Han, T. Urase, N. Huu Hao, J. Hu, S.L. Ong, Insight into metabolic and cometabolic activities of autotrophic and heterotrophic microorganisms in the biodegradation of emerging trace organic contaminants, Bioresour. Technol., 146 (2013) 721-731.

[45] W. Baran, E. Adamek, J. Ziemianska, A. Sobczak, Effects of the presence of sulfonamides in the environment and their influence on human health, J. Hazard. Mater., 
196 (2011) 1-15.

[46] P. Sukul, M. Spiteller, Sulfonamides in the environment as veterinary drugs, in:

G.W. Ware (Ed.) Reviews of Environmental Contamination and Toxicology, Vol 187, 2006, pp. 67-101. 
Table 1. The parametric control for the anaerobic digestion and sequencing batch reactor processes

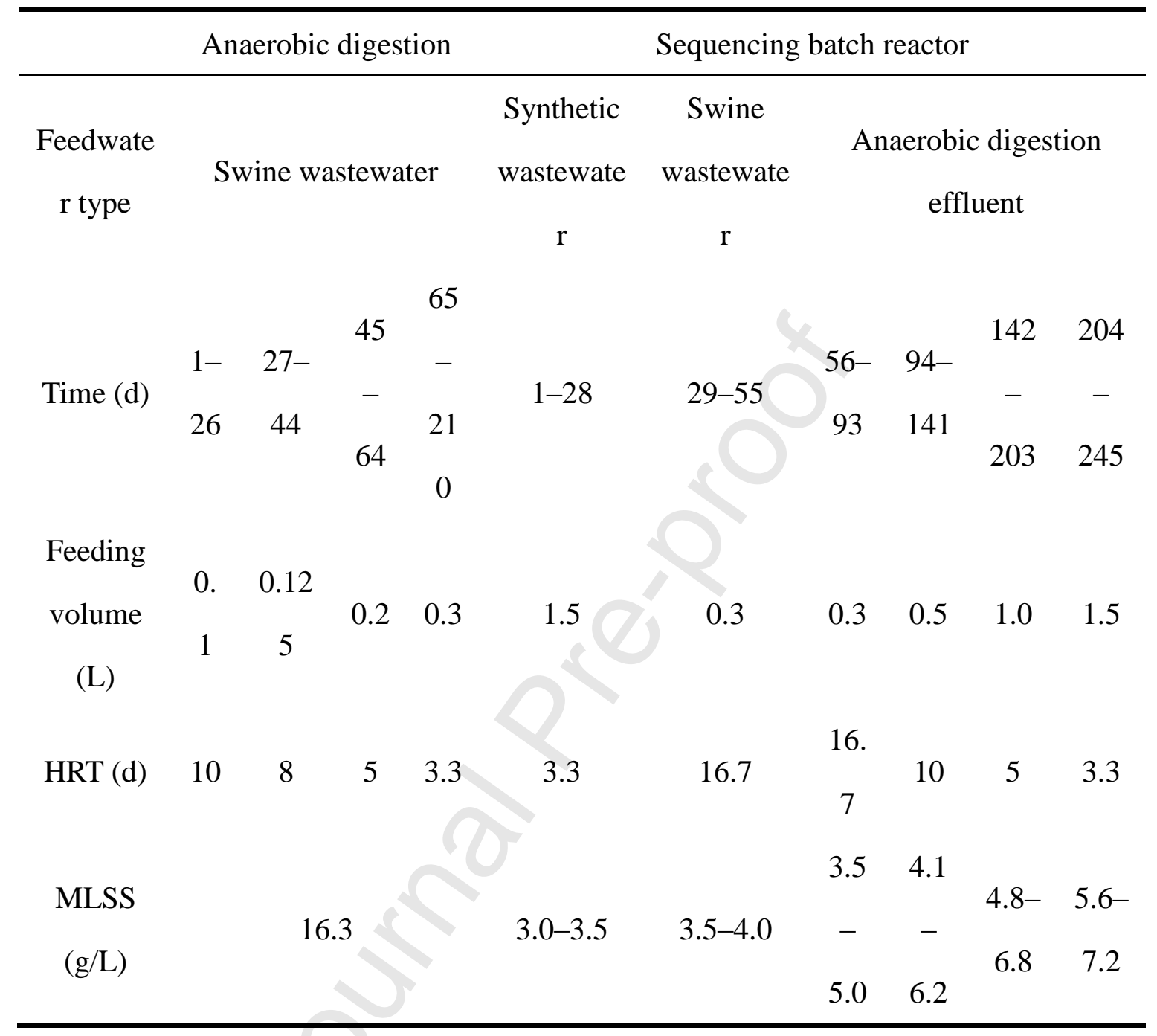

Note: HRT means hydraulic residence time; MLSS means mixed liquor suspended solids. 
Table 2. The characteristics of synthetic and swine wastewater ${ }^{a}$

\begin{tabular}{|c|c|c|c|c|c|}
\hline \multirow[b]{2}{*}{$\begin{array}{c}\text { Parameter } \\
\text { s }\end{array}$} & \multirow[b]{2}{*}{ Unit } & \multirow[b]{2}{*}{$\begin{array}{l}\text { Synthetic } \\
\text { wastewater }\end{array}$} & \multicolumn{3}{|c|}{ Swine wastewater } \\
\hline & & & $\begin{array}{l}\text { Anaerobic } \\
\text { digestion } \\
\text { influent }\end{array}$ & $\begin{array}{l}\text { Anaerobic } \\
\text { digestion } \\
\text { effluent }\end{array}$ & $\begin{array}{c}\text { Storage tank } \\
\text { effluent }\end{array}$ \\
\hline $\mathrm{pH}$ & -- & 6.8 & 7.8 & 7.7 & 7.7 \\
\hline COD & $\mathrm{mg} / \mathrm{L}$ & 1210 & $\begin{array}{c}5683(4970- \\
7010)\end{array}$ & $\begin{array}{c}1097(850- \\
1245)\end{array}$ & $657(560-752)$ \\
\hline $\mathrm{NH}_{3}-\mathrm{N}$ & $\mathrm{mg} / \mathrm{L}$ & 300 & $836(734-892)$ & $661(520-842)$ & $642(555-705)$ \\
\hline $\mathrm{NO}_{3}{ }^{-}-\mathrm{N}$ & $\mathrm{mg} / \mathrm{L}$ & -- & $36(22-62)$ & $10(8-11)$ & $11(5-16)$ \\
\hline $\mathrm{NO}_{2}^{-}-\mathrm{N}$ & $\mathrm{mg} / \mathrm{L}$ & -- & $14(12-14)$ & $10(9-10)$ & $11(6-16)$ \\
\hline $\mathrm{TN}$ & $\mathrm{mg} / \mathrm{L}$ & 500 & $865(780-945)$ & $685(540-883)$ & $669(575-743)$ \\
\hline $\mathrm{PO}_{4}{ }^{3-}-\mathrm{P}$ & $\mathrm{mg} / \mathrm{L}$ & 44 & $44(42-48)$ & $20(17-23)$ & $25(22-28)$ \\
\hline $\mathrm{TP}$ & $\mathrm{mg} / \mathrm{L}$ & 44 & $52(43-56)$ & $20(18-24)$ & $27(26-28)$ \\
\hline
\end{tabular}

Note: ${ }^{a}$ Mean (minimum-maximum), $\mathrm{n}=3$. 


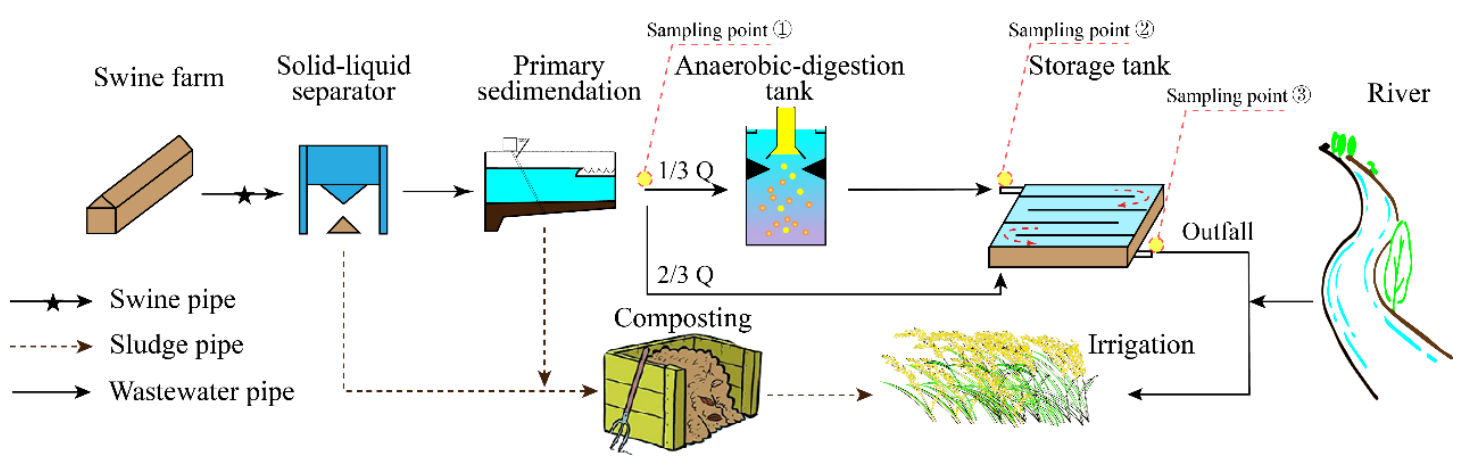

Fig. 1. The flow chart of on-site swine waste treatment system. 


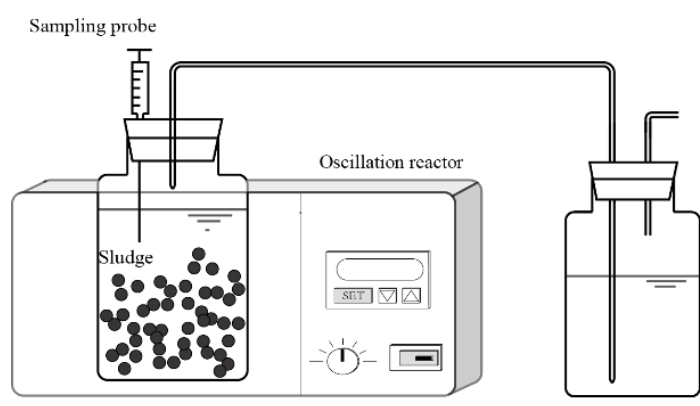

Anaerobic digestion reactor

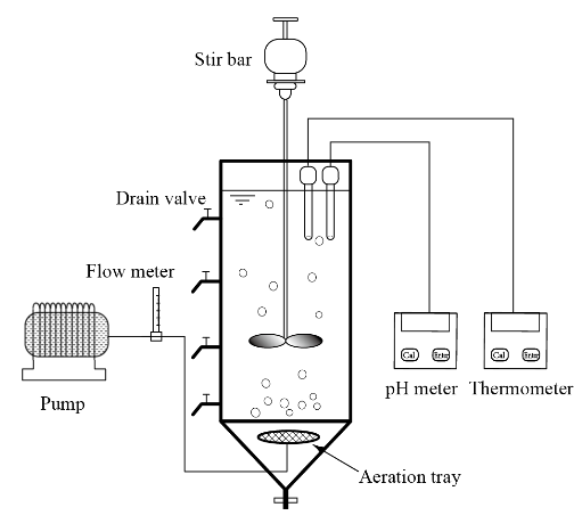

Sequencing batch reactor

Fig. 2. The schematic diagram of anaerobic digestion and sequencing batch reactor 

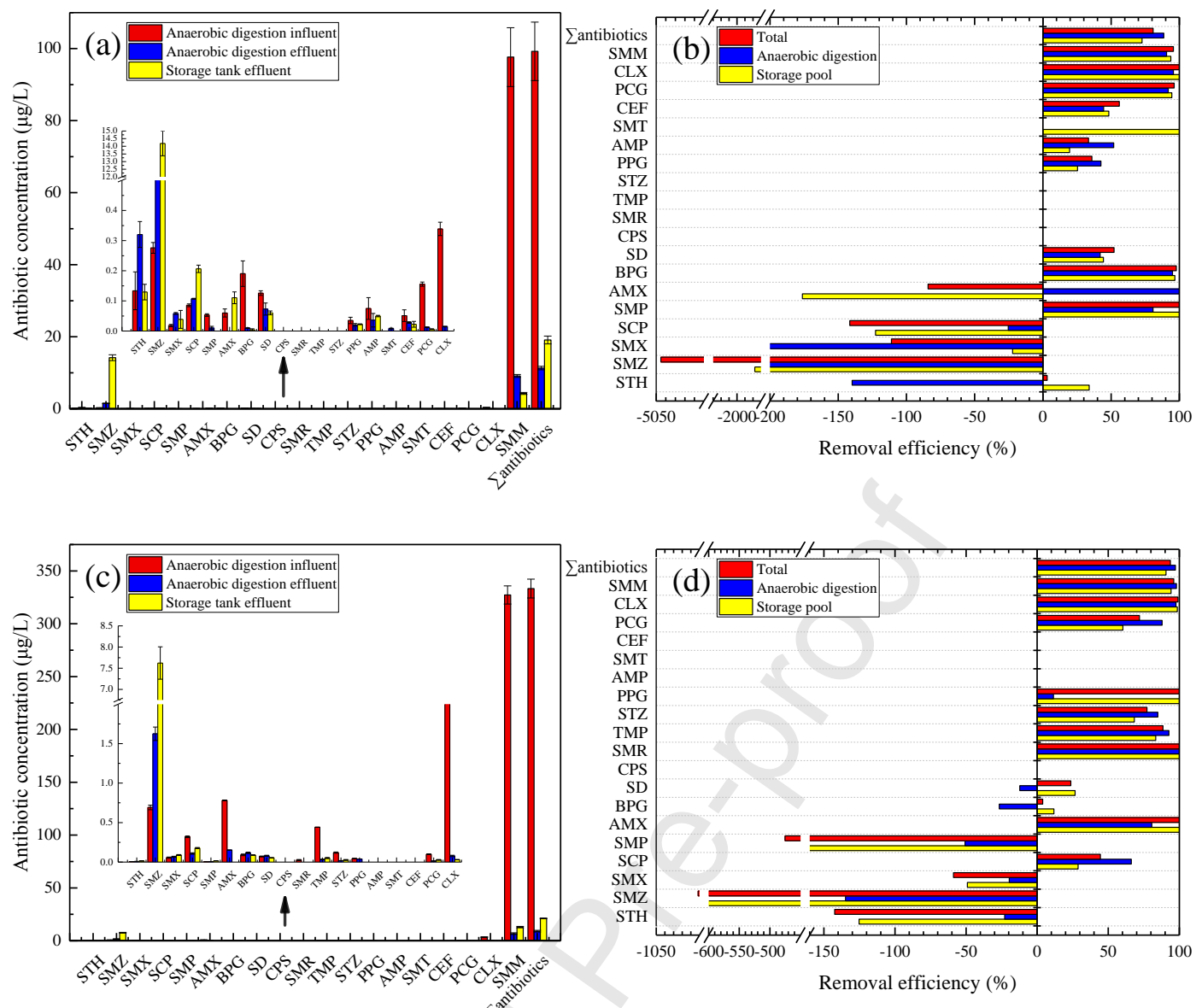

Fig. 3. The concentrations and removal efficiencies of antibiotics in the on-site swine wastewater treatment plant on August 27, $2018(\mathrm{a}, \mathrm{b})$ and October 17, 2018 (c, d). The "Total" refers to the overall removal efficiencies of antibiotics by anaerobic digestion and storage tank. The error bars were based on three independent samples. Abbreviations: STH: sulfathiazole; SMZ: sulfamethazine; SMX: sulfamethoxazole; SCP: sulfachlorpyridazine; SMP: sulfamethoxypyridazine; AMX: amoxicillin; BPG: benzathine penicillin G; SD: sulfadiazine; CPS: cefpirome sulfate; SMR: sulfamerazine; TMP: trimethoprim; STZ: sulfamethizole; PPG: procaine penicillin G; AMP: ampicillin; SMT: sulfamethazine; CEF: ceftiofur; PCG: benzylpenicillin potassium; CLX: cloxacillin sodium; SMM: sulfamonomethoxine. 

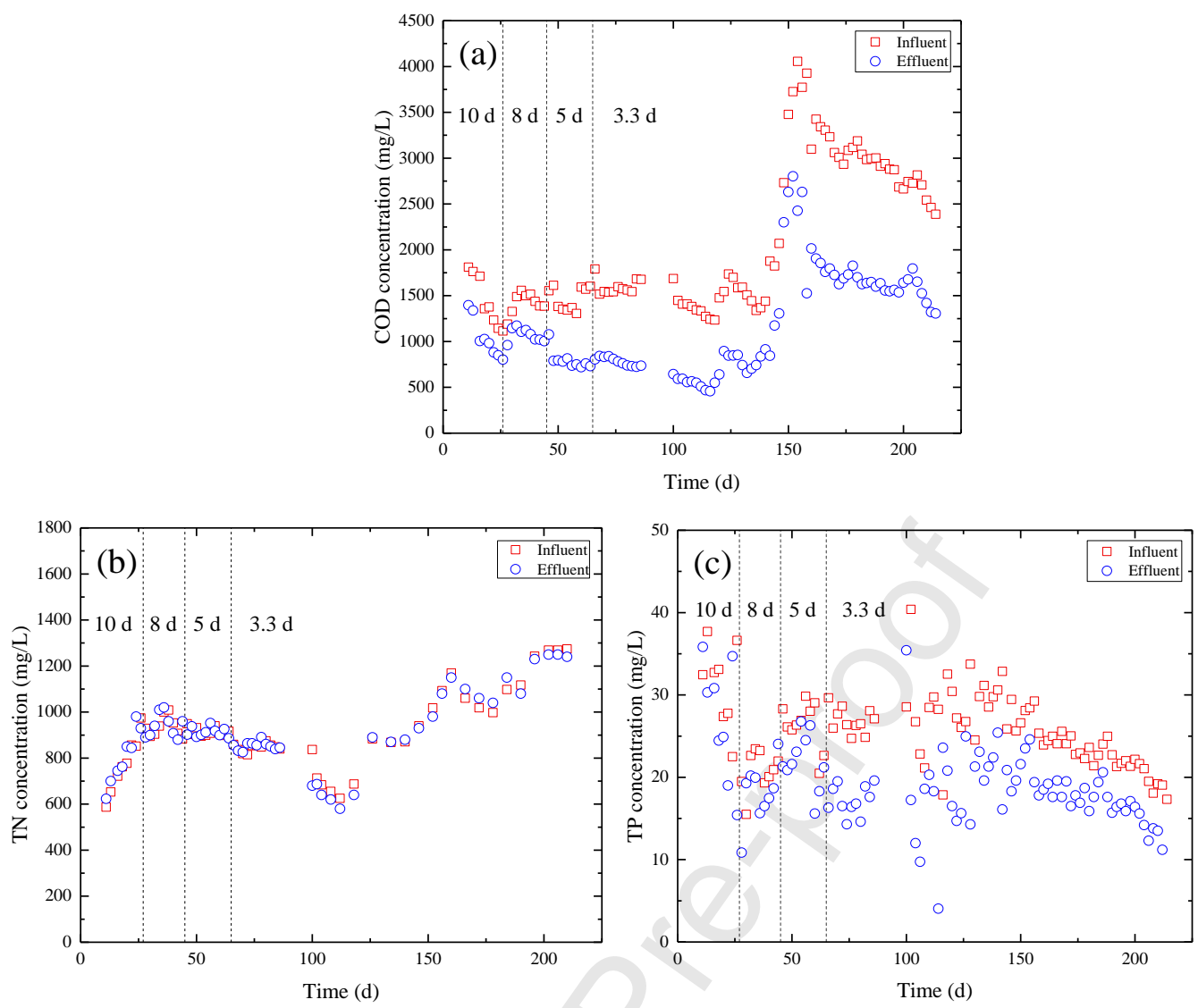

Fig. 4. The concentrations of COD (a), TN (b) and TP (c) during the anaerobic digestion process. The influent referred to the solution in the anaerobic digestion reactor after the addition of feedwater. The hydraulic residence time of each period has been shown in the figures. 

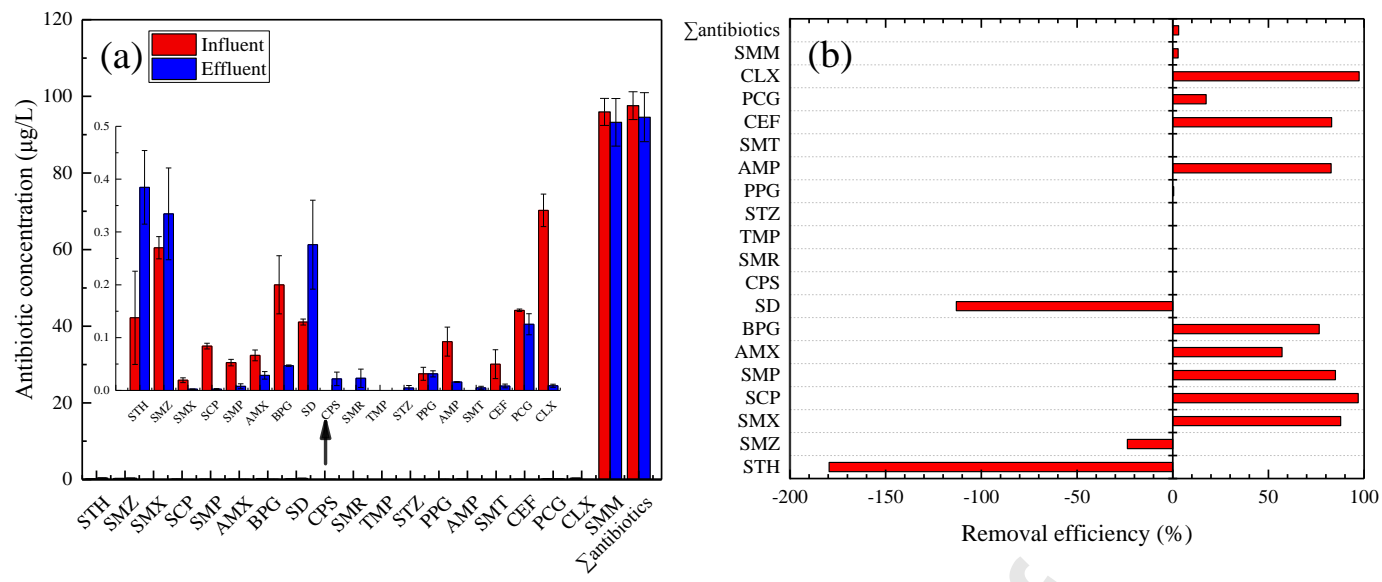

Fig. 5. The concentrations (a) and removal efficiencies (b) of antibiotics for the anaerobic digestion process on the $120^{\text {th }}$ day. The error bars were based on two independent samples. 

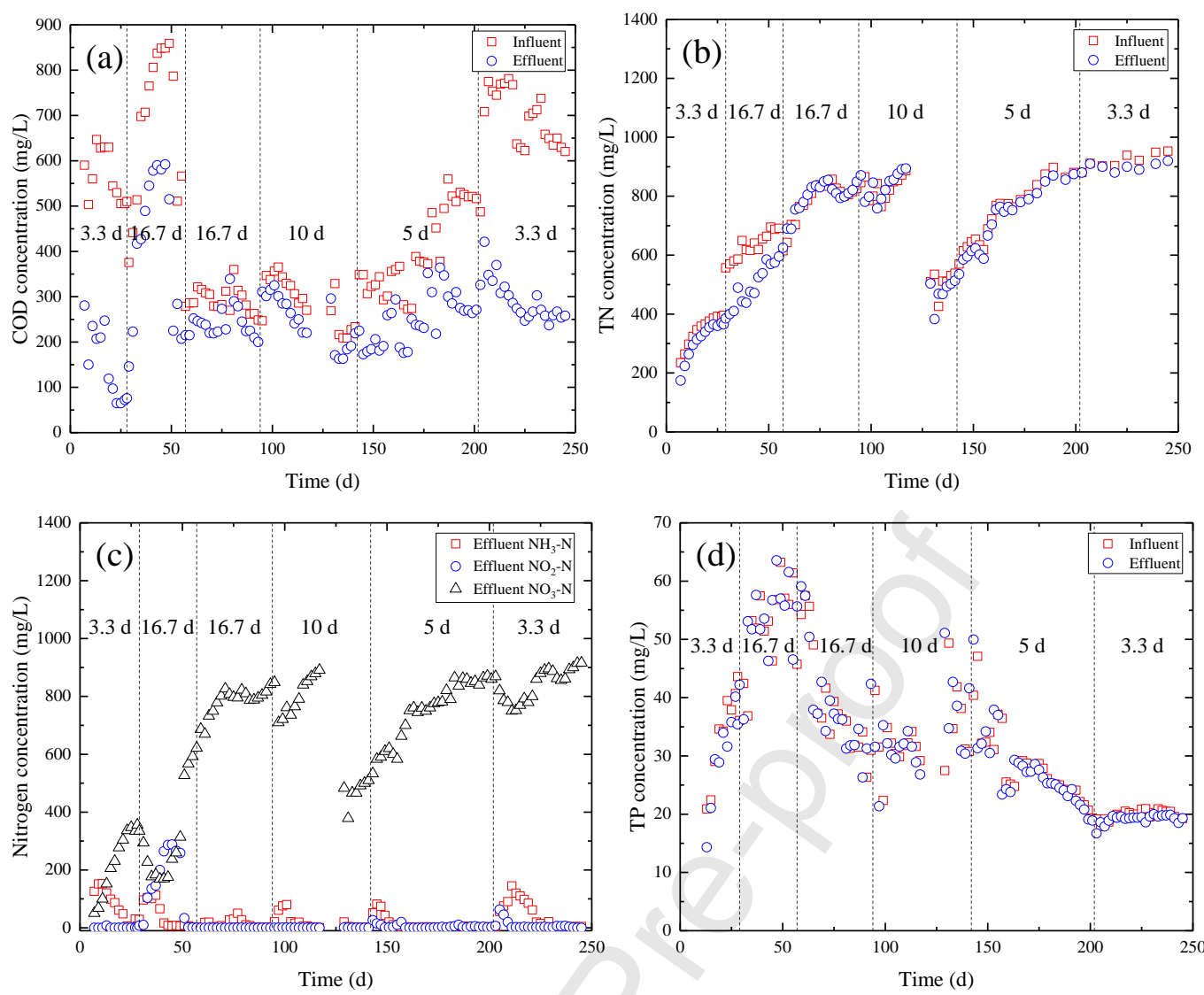

Fig. 6. The concentrations of $\operatorname{COD}(a)$, nitrogen (b, c), and phosphorus (d) during the aerobic degradation process. The influent referred to the solution in sequencing batch reactor after the addition of feedwater. The hydraulic residence time of each period has been shown in the figures. 

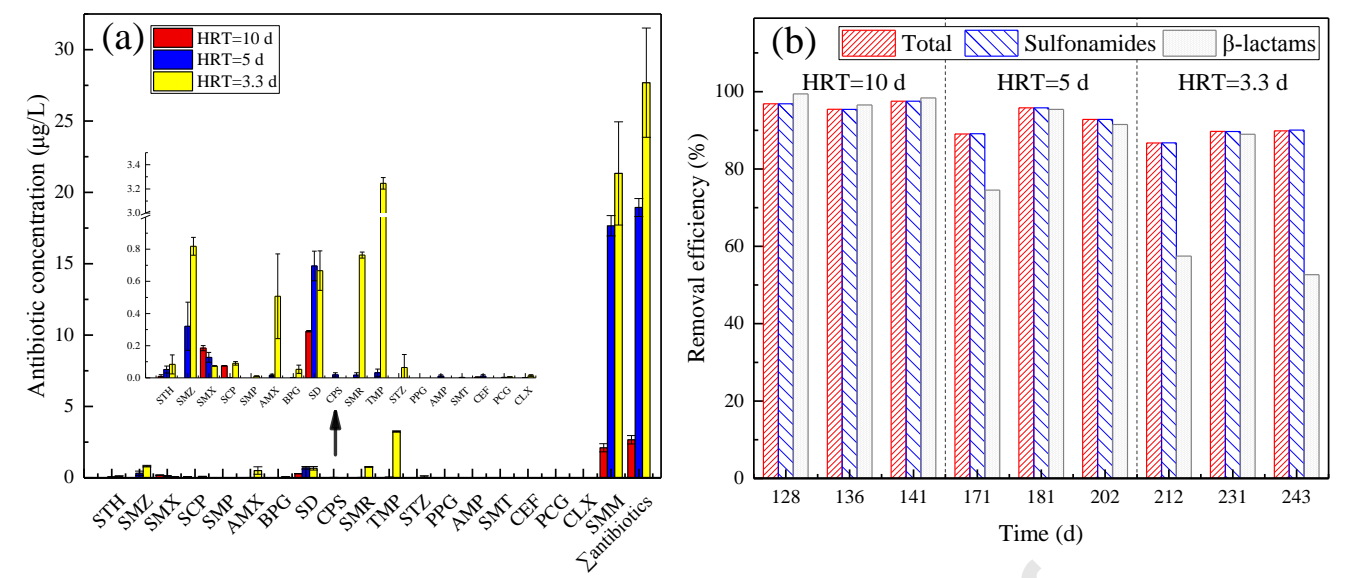

Fig.7. The concentrations (a) and removal efficiencies (b) of antibiotics under different hydraulic residence times for the aerobic degradation process. The concentrations were for samples collected in the $141^{\text {st }}, 202^{\text {nd }}$ and $243^{\text {rd }}$ day during the periods with HRTs of 10 , 5 and 3.3 days, respectively. The "Total" refers to the removal efficiencies of all antibiotics including sulfonamides and $\beta$-lactams. The hydraulic residence time of each period has been shown. The error bars were based on two independent samples. 


\section{Declaration of interests}

$\otimes$ The authors declare that they have no known competing financial interests or personal relationships that could have appeared to influence the work reported in this paper.

$\square$ The authors declare the following financial interests/personal relationships which may be considered as potential competing interests: 


\section{Graphical abstract}

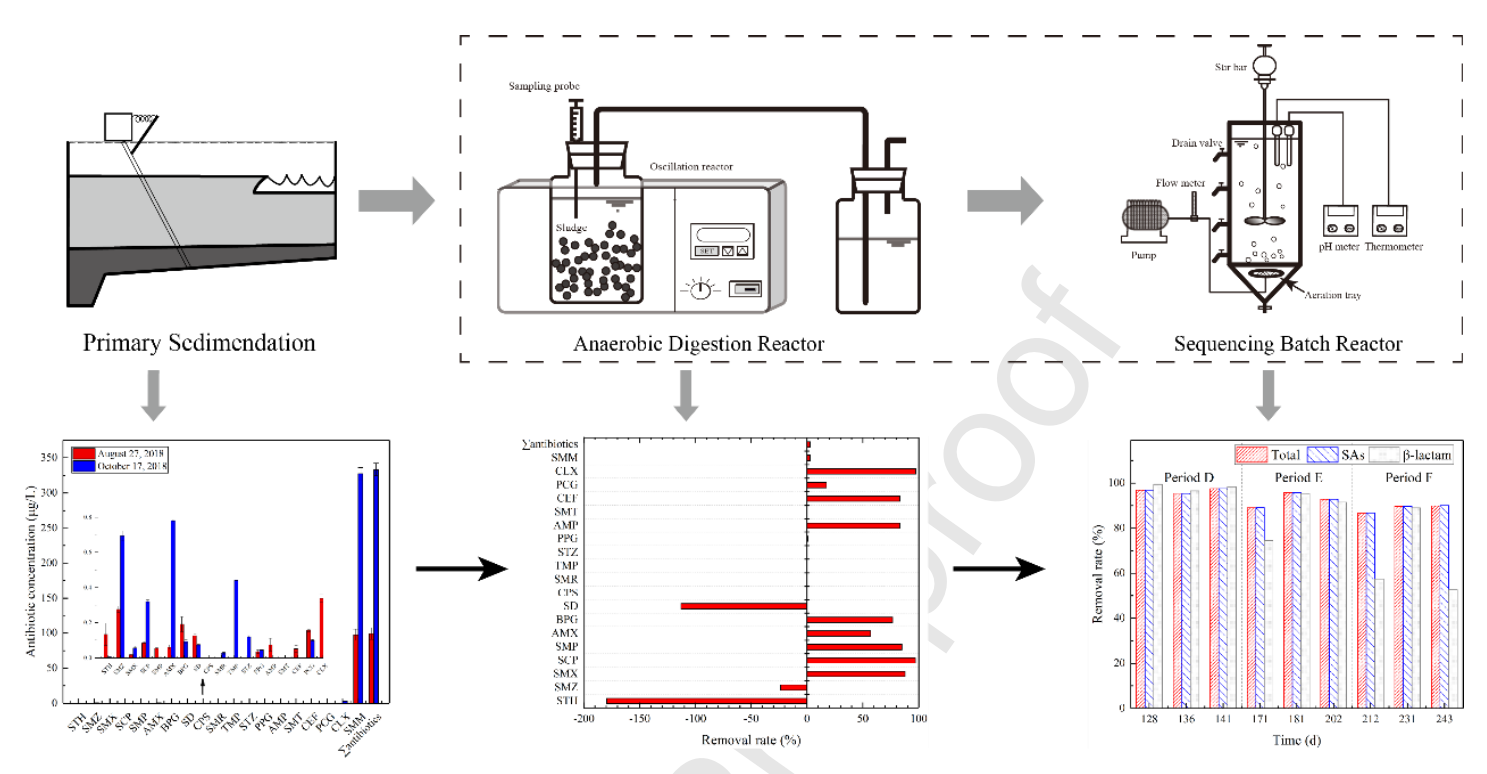




\section{Highlights}

The total antibiotic concentrations in swine wastewater were 99.2 339.3 $\mu \mathrm{g} / \mathrm{L}$.

The combined anaerobic and aerobic treatment removed 95\% COD and 92\% antibiotics.

$>$ The fate of antibiotics should be a combined result of biodegradation, adsorption and transformation.

$>$ Higher HRT for aerobic process resulted in better antibiotic degradation performance. 


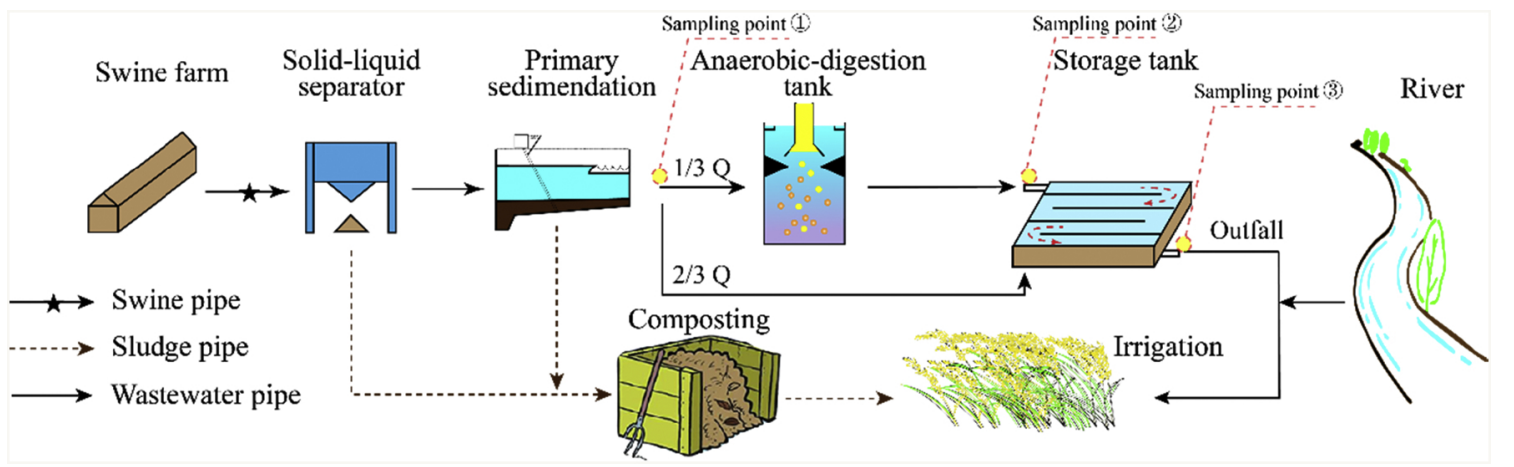

Figure 1 
Sampling probe

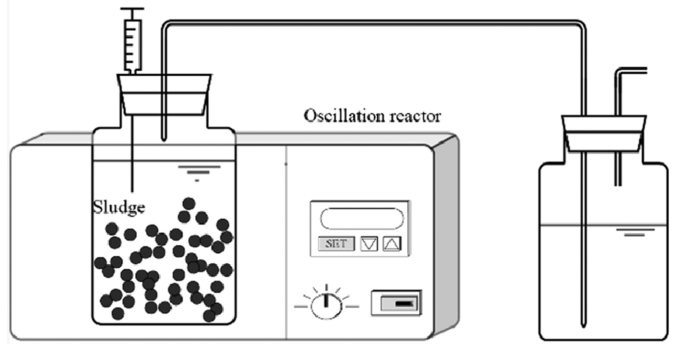

Anaerobic digestion reactor

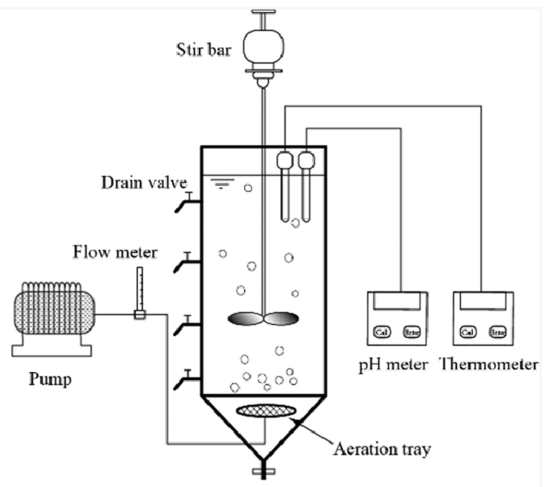

Sequencing batch reactor

Figure 2 

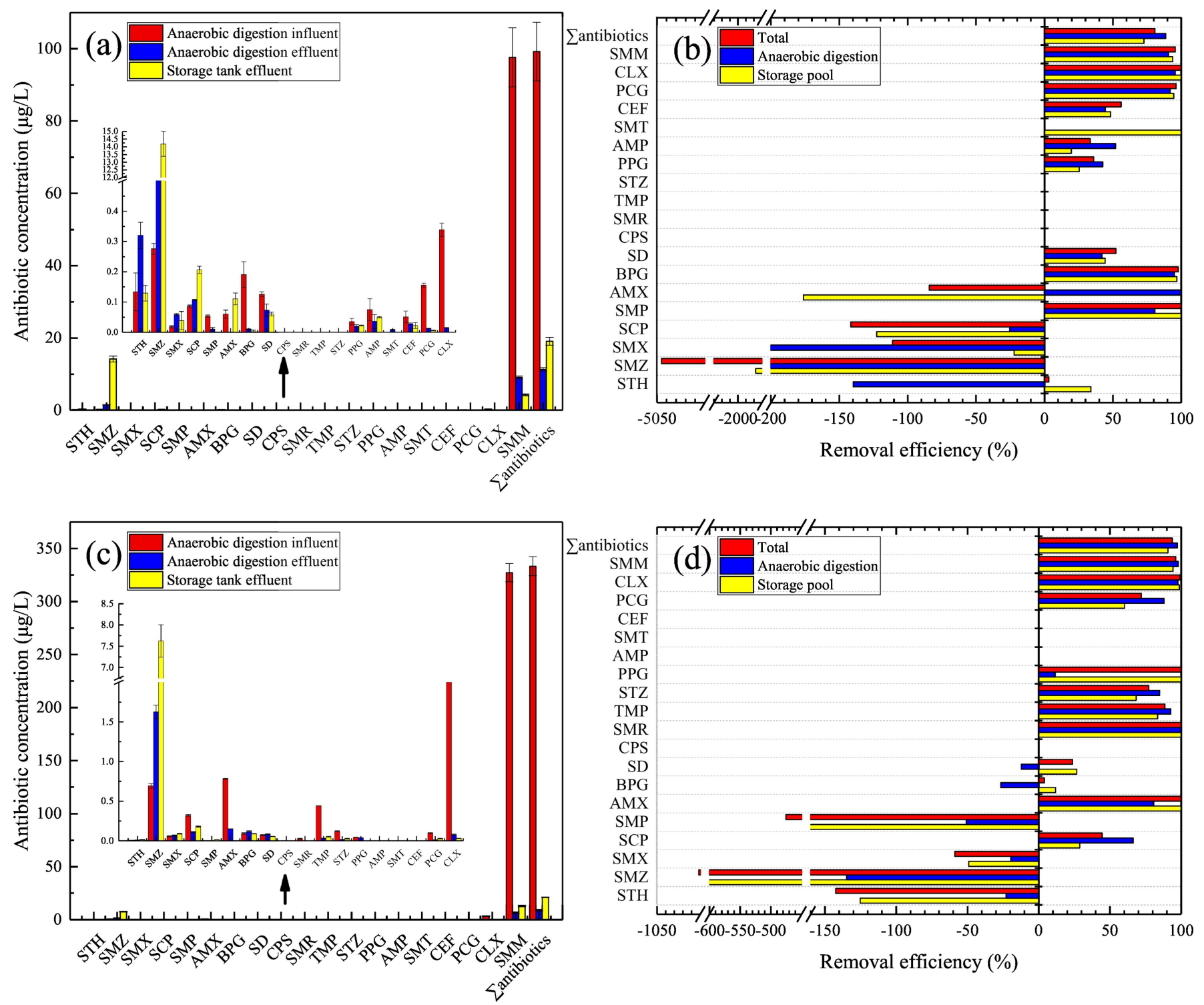

Figure 3 

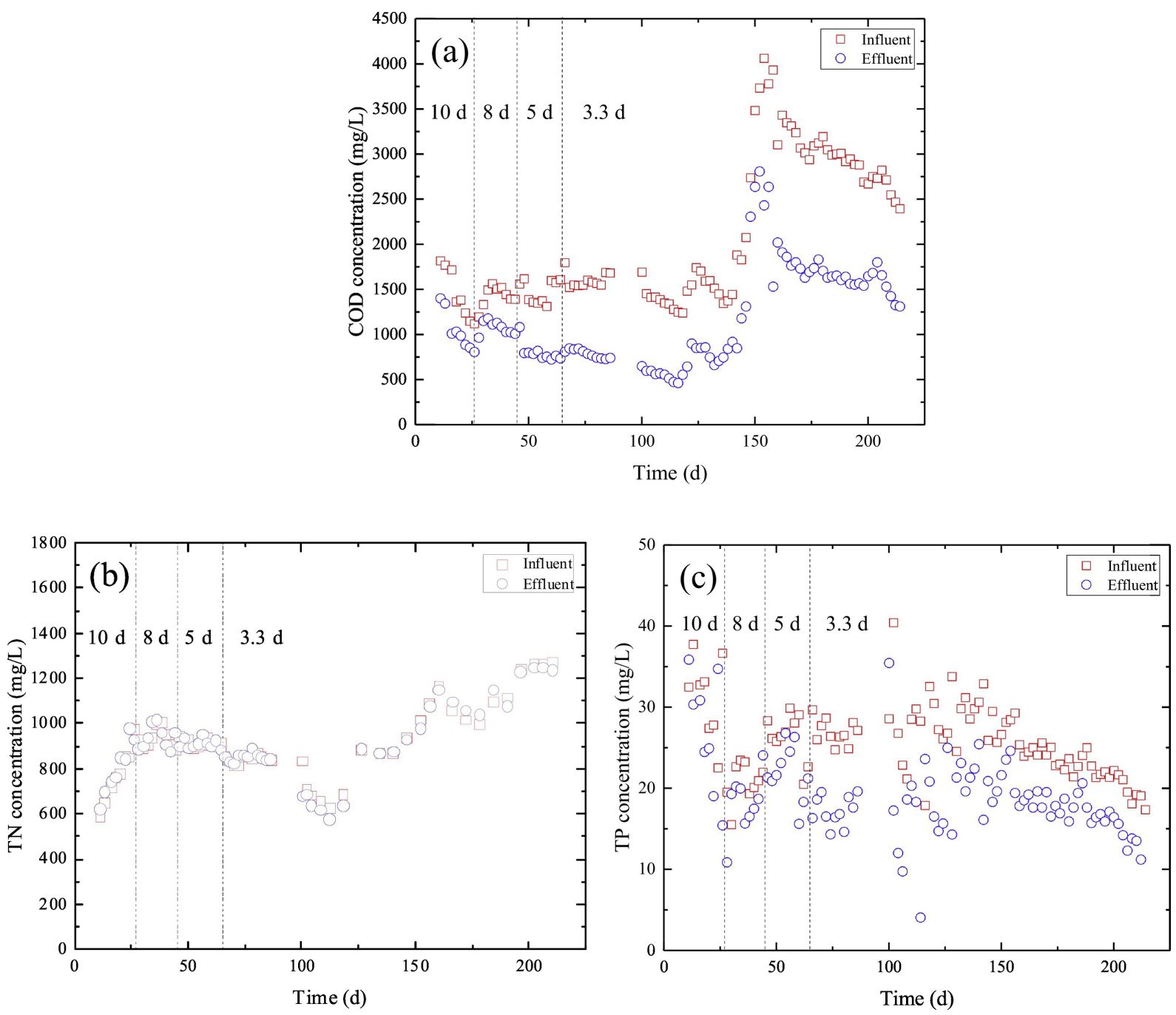

Figure 4 

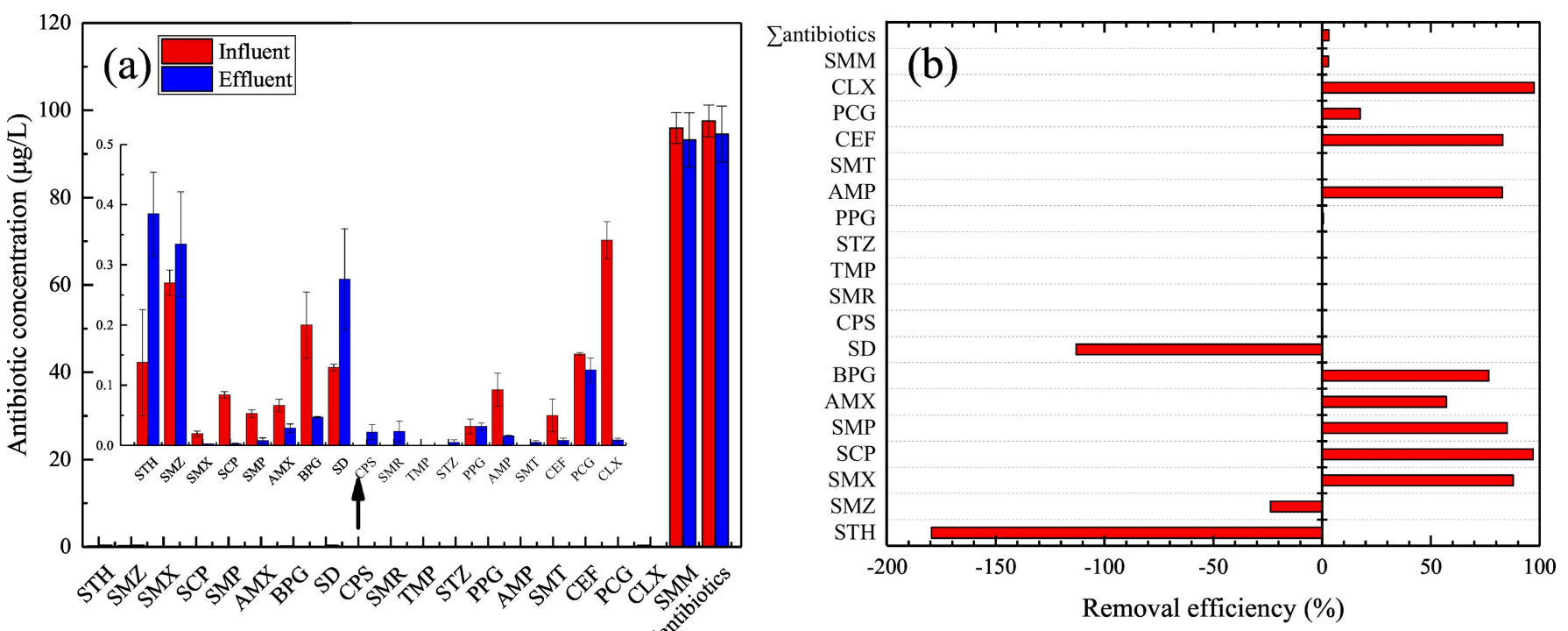

Figure 5 

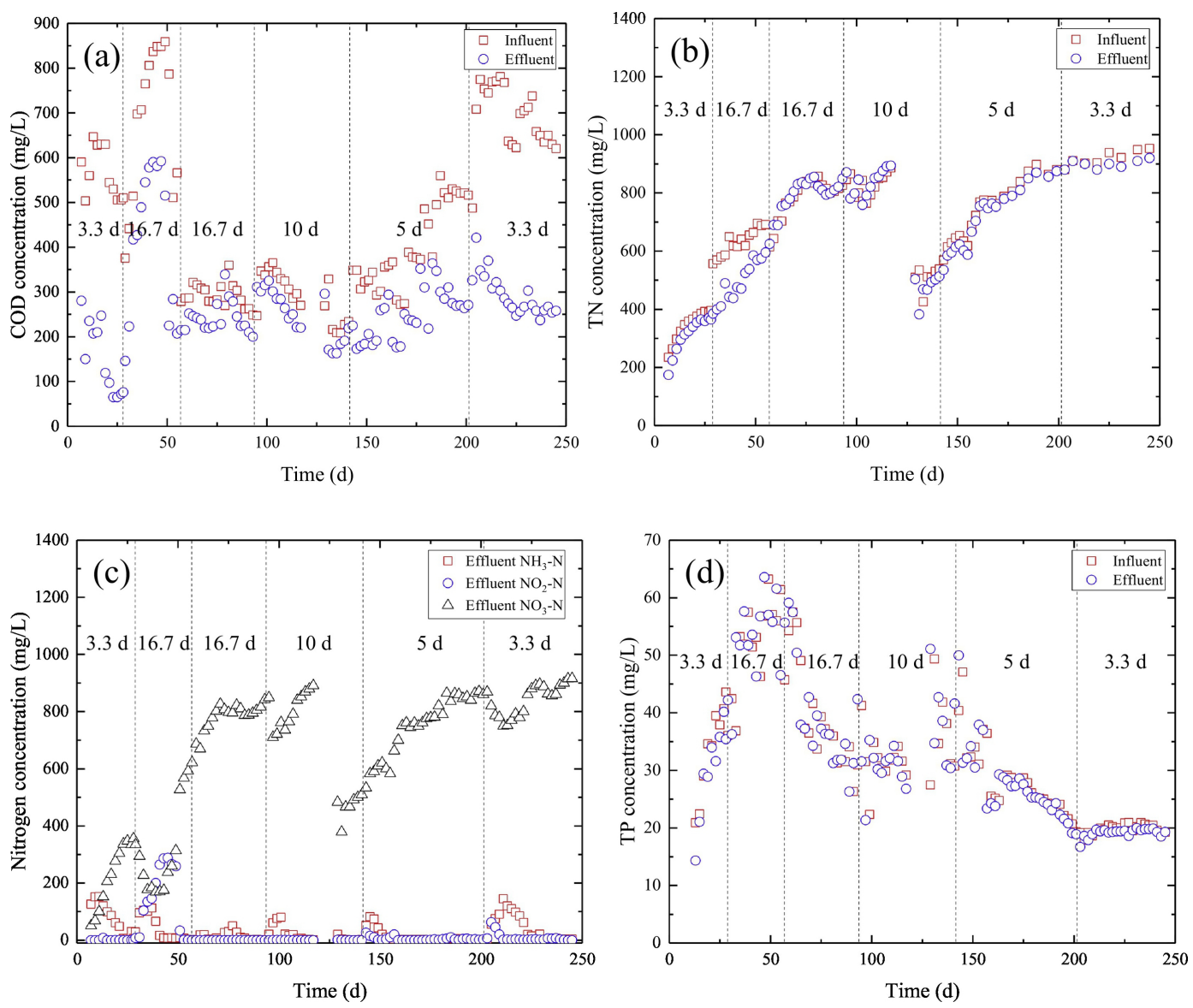

Figure 6 


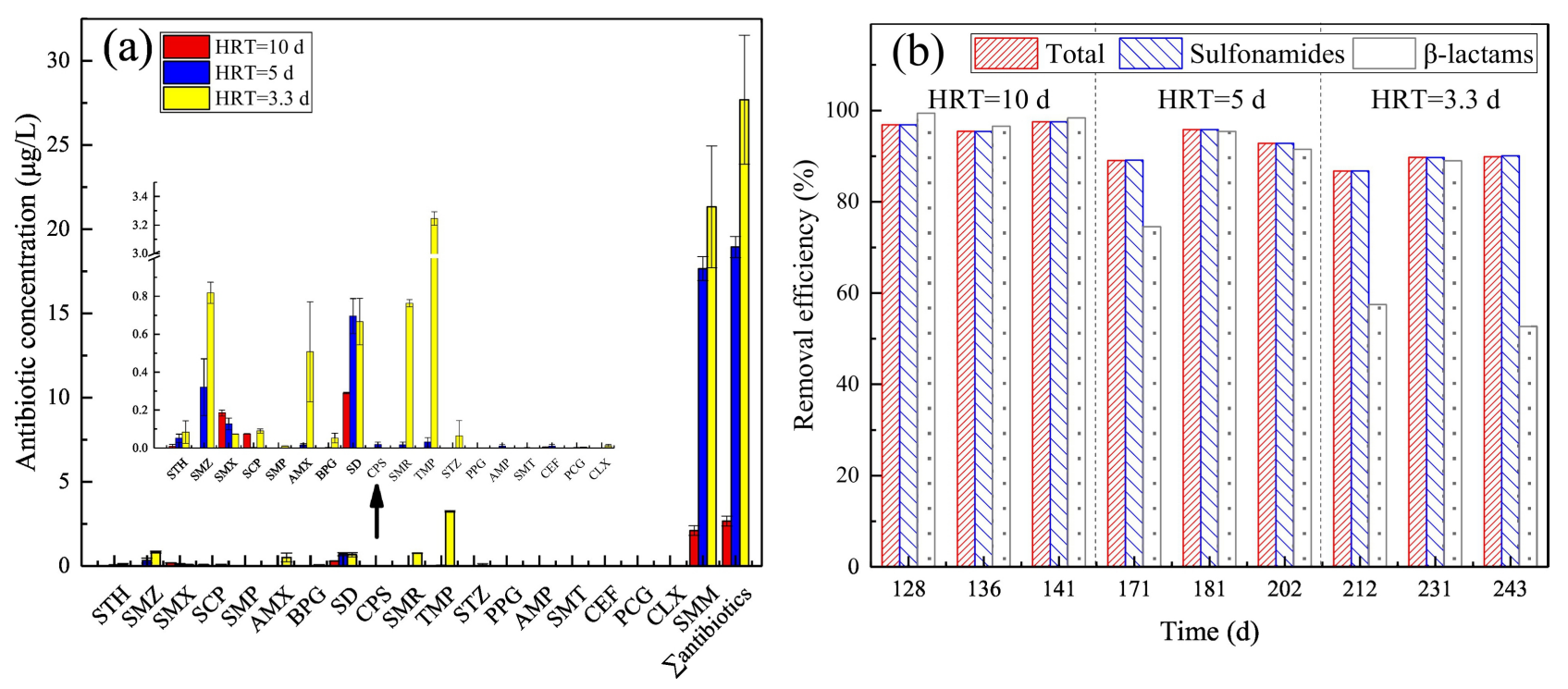

Figure 7 